NASA/TM-2000-210345

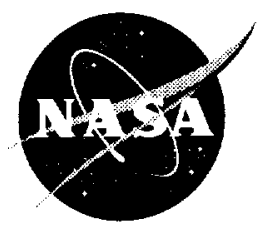

\title{
Investigation of Instabilities and Heat Transfer Phenomena in Supercritical Fuels at High Heat Flux and Temperatures
}

Diane L. Linne, Michael L. Meyer, and Donald C. Braun

Glenn Research Center, Cleveland, Ohio

Dennis J. Keller

RealWorld Quality Systems, Cleveland, Ohio

Prepared for the

36th Joint Propulsion Conference and Exhibit cosponsored by AIAA, ASME, SAE, and ASEE

Huntsville, Alabama, July 16-19, 2000

National Aeronautics and

Space Administration

Glenn Research Center 
Available from

NASA Center for Aerospace Information 7121 Standard Drive

Hanover, MD 21076

Price Code: A03
National Technical Information Service 5285 Port Royal Road Springfield, VA 22100 Price Code: A03 


\title{
INVESTIGATION OF INSTABILITIES AND HEAT TRANSFER PHENOMENA IN SUPERCRITICAL FUELS AT HIGH HEAT FLUX AND TEMPERATURES
}

\author{
Diane L. Linne, Michael L. Meyer, and Donald C. Braun \\ National Aeronautics and Space Administration \\ Glenn Research Center \\ Cleveland, Ohio 44135 \\ Dennis J. Keller \\ RealWorld Quality Systems \\ Cleveland. Ohio 44116
}

$\underline{\text { Abstract }}$

A series of heated tube experiments was performed to investigate fluid instabilities that occur during heating of supercritical fluids. In these tests, JP-7 flowed vertically through small diameter tubes at supercritical pressures. Test section heated length, diameter, mass flow rate, inlet temperature, and heat flux were varied in an effort to determine the range of conditions that trigger the instabilities. Heat flux was varied up to $4 \mathrm{BTU} / \mathrm{in} .{ }^{2} / \mathrm{s}$, and test section wall temperatures reached as high as $1950^{\circ} \mathrm{F}$.

A statistical model was generated to explain the trends and effects of the control variables. The model included no direct lineareffect of heat flux on the occurrence of the instabilities. All terms involving inlet temperature were negative, and all terms involving mass flow rate were positive. Multiple tests at conditions that produced instabilities provided inconsistent results. These inconsistencies limit the use of the model as a predictive tool. Physical variables that had been previously postulated to control the onset of the instabilities, such as film temperature, velocity, buoyancy, and wall-to-bulk temperature ratio, were evaluated here. Film temperatures at or near critical occurred during both stable and unstable tests. All tests at the highest velocity were stable, but there was no functional relationship found between the instabilities and velocity, or a combination of velocity and temperature ratio. Finally, all of the unstable tests had significant buoyancy at the inlet of the test section, but many stable tests also had significant buoyancy forces.

Copyright $(C) 2000$ by the American Institute of Aeronautics and Astronautics, Inc. No copyright is asserted in the United States under Title 17, U.S. Code. The U.S. Government has a royalty-free license to exercise all rights under the copyright claimed herein for Governmental Purposes. All other rights are reserved by the copyright owner.
Introduction

Current activities in both aeronautics and space have increased the importance of research into hydrocarbon fuels used as a coolant and operating at or near supercritical conditions in high temperature environments. Research in hypersonic propulsion for aeronautics shows increased heat loads on the engine and related systems. ${ }^{1.2}$ These heat fluxes are on the same order of magnitude as typical in rocket engines, but must now be handled with the lower fuel flow rates available in aircraft engines. In addition. interest in combined cycle propulsion for launch vehicles has increased the possibility of hydrocarbon fuels being used to maintain fuel commonality and ease operational requirements. ${ }^{3}$ While hydrocarbon fuels are used as the regenerative coolant in some current rocket engines (e.g., the RD 180) ${ }^{4}$ this combined cycle propulsion system is being proposed for a reusable, instead of an expendable. vehicle.

The NASA Glenn Research Center's Turbomachinery and Propulsion Systems Division and the Wright Laboratory's Fuels and Lubrication Division have a joint program in high-temperature fuel system research. The basic goal is to develop an understanding of fuel system behavior as a function of temperature, pressure, residence time, heat flux, and surface effects within the fuel system components. Previous tests were performed using JP-7 as the coolant, with the objective of measuring coking characteristics and material interactions at relatively high heat flux (4 to $5 \mathrm{BTU} / \mathrm{in} .{ }^{2} / \mathrm{s}$ ) and wall temperatures $\left(1800^{\circ} \mathrm{F}\right) .{ }^{5}$ These tests were dominated by instabilities that often caused critical failure of the thin-walled test sections. Although these instabilities were identified by the acoustic resonance of the test section, it is likely that it is actually a fluid flow instability that causes the tube to resonate when matching its natural frequency. Microstructural analysis of the failed test sections indicated 
that some failures were due to stress fatigue (caused by the vibrations) and some failures were due to high temperature fatigue (caused by a sudden reduction in convective heat transfer).

\section{Background}

Pressure and flow oscillations in convective heat transfer experiments have been reported in the literature for many years. ${ }^{5-13}$ These phenomena are of significant interest due to the impact that they have on the heat transfer system, which includes test section destruction, heat transfer enhancement, and the potential to drive combustion instabilities. It is important to note that these instabilities are not merely an artifact of the single tube experiments. In tests with a rocket engine thrust chamber cooled with supercritical methane ${ }^{6}$ pressure fluctuations were observed in the cooling circuit that were attributed to the heat transfer.

The test conditions and coolants with which oscillations have been observed are wide ranging, as are the physical explanations of the cause of these oscillations. Further complicating the problem is the fact that many of the experiments in which oscillations have been reported did not include or lend themselves to the type of instrumentation required to characterize the instabilities. Because similar flow instabilities have been observed in subcritical boiling experiments, much of the literature focuses on large property variations due to heating the coolant as initiating the oscillations. A significant challenge of identifying the cause of these oscillations is that several types of oscillations can occur. Reference 7 characterized a large number of oscillation types. This effort was conducted with liquid nitrogen and liquid hydrogen coolants and identified five oscillation types: open pipe acoustic, Helmholtz, "supercritical mode," plug flow, and "sawtooth and negative pulse." In a separate study with hydrogen, ${ }^{8}$ both lateral and vertical (along the tube axis) oscillations were identified by accelerometers, and it was noted that heat transfer enhancement only occurred with the higher frequency lateral oscillations.

Reference 9 describes experiments similar to the present work with RP-1 and DECH flowing through electrically heated tubes and documents the destructive effect of oscillations on the test sections. These test were conducted at 700 psia. By plotting heat flux versus wall temperature they were able to identify a boiling-like heat transfer enhancement which began when the wall temperature reached the point where specific heat was a local maximum. A mechanism for initiating the instabilities was proposed based on large variations in viscosity near the wall at temperatures near critical. ${ }^{9,10}$ The decrease in liquid viscosity at higher temperatures would cause the boundary layer to thin, increasing the heat transfer coefficient. This increase in heat transfer coefficient would decrease the film temperature with a resultant increase in viscosity, and the cycle would repeat. Reference 9 further states that for these fuels at reduced pressures (i.e., operating pressure divided by critical pressure) greater than 2.5 viscosity variations are small, and therefore the probability of instabilities occurring should be decreased. In limited tests at 2000 psia (reduced pressure about 6), they observed no oscillations. However, reference 5 describes destructive oscillations in tests with JP-7 at reduced pressures of about three.

In reference 11 , the occurrence of instabilities shows a strong correlation to velocity and wall-to-bulk temperature ratio in tests with supercritical propane. A more recent effort ${ }^{12.13}$ focused on the influence of buoyancy forces in establishing instabilities. In this study, aimed at utilizing the enhancement to heat transfer that has been reported for oscillating supercritical flows near the critical point, severe instabilities and a suppression of heat transfer were observed. It was also demonstrated that the buoyancy forces could be counteracted, the instabilities damped, and heat transfer enhanced significantly with the use of turbulating inserts in the coolant passages.

Although these previous works all suggest a reason or mechanism for the instabilities, the conclusions are not consistent from one study to another. In addition, most of the instabilities were studied as an unexpected phenomena that occurred in the course of pursuing some other primary objectives. Therefore, a series of tests was performed to determine the set of conditions that cause these instabilities in supercritical JP-7.

\section{Design of Experiment}

A design of experiments (DOE) was performed to minimize the number of tests required and to maximize the significance of the results. The first step was to identify all of the variables that could cause, or contribute to, the fluid instabilities. These control variables were identified in several groups and are discussed below

Pressure.-The operating pressure of the fuel in the test section, especially as it relates to the critical pressure of the fuel $\left(P_{c r}=260 \mathrm{psi}\right)$, can change the effect that the other variables will have on the instabilities.

Temperature.- The fuel enters the test section with a bulk fluid temperature less than critical temperature $\left(T_{c r}=760^{\circ} \mathrm{F}\right)$ and can transition through $T_{c r}$ before exiting the test section. It has also been suggested that film temperature may be the key. Analysis of previous data with JP $-7^{5}$ indicates that film temperature was in the vicinity of $T_{\mathrm{cr}}$ whenever instabilities started. Finally, in reference 9 the authors stated that the instabilities started when the coolant-side wall temperature approached the critical temperature of the fuel. However, in previous 
tests, ${ }^{5}$ the wall temperatures were significantly higher than the critical temperature of the JP-7 at the start of the instabilities. Figure 1 graphically depicts these possible temperature profiles at the start of the instabilities.

Heat flux.-In some experiments where instabilities occurred during the investigation of other objectives, the limited number of data points led to the conclusion that heat flux is the driving factor. However, it is likely that heat flux is only interactive with other factors. For example. changing heat flux will affect wall, bulk, and film temperatures.

Test section geometry.-Different test section lengths will change the natural frequency of the test section and the fluid in it, thus affecting whether the fluid instability will be transferred into the wall and become audible. Different lengths will also affect bulk fluid temperatures at the same heat flux. Test section inner diameter will affect the bulk fluid, film, and wall temperatures at the same heat flux. Diameter could also affect flow interactions between the boundary layer and bulk flow.

Flow rate.-Instabilities could be affected by how many pounds are available to absorb the heat (mass flow $\mathrm{rate}, \mathrm{lbm} / \mathrm{s}$ ), by how quickly the fluid moves (velocity, $\mathrm{ft} / \mathrm{s}$ ), or by the total volume available to absorb the heat (volume flow rate, $\mathrm{ft}^{3} / \mathrm{s}$ ). By setting any one of these variables (at constant diameter), the other two flow rate variables are also set.

Buoyancy forces.-When heating an upward vertical flow, buoyancy forces act to impair heat transfer. Buoyancy forces are measured by the Grashof number and are compared to the Reynolds number to determine if they are significant. This complicates the statistical analysis, since these nondimensional numbers are already a compilation

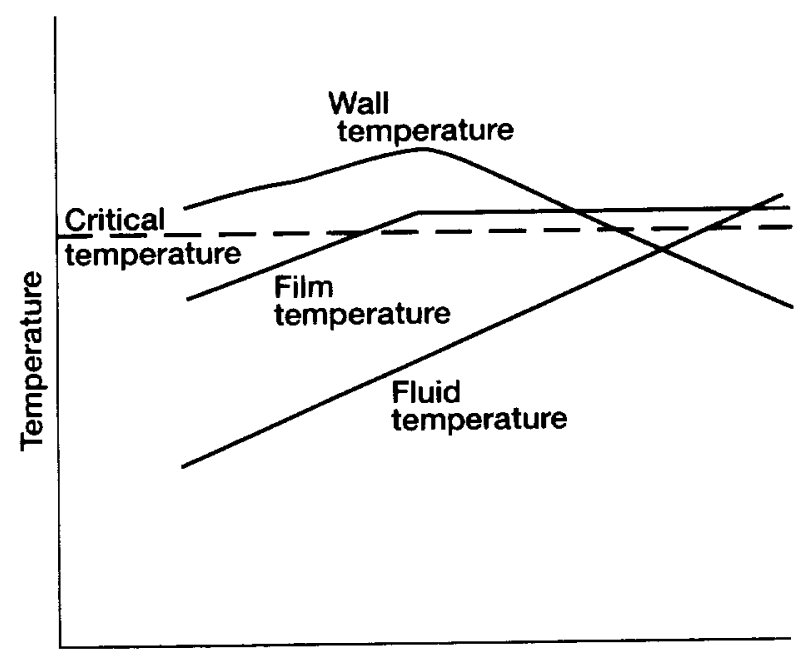

Test section axial distance

Figure 1.-Possible temperature profiles at start of instabilities. of other factors already discussed. Grashof number is dependent on densities at both bulk and film temperature, film viscosity, and test section diameter. Reynolds number is dependent on mass flow rate, diameter, and bulk viscosity. Higher fluid velocities and inlet temperatures cause buoyancy forces to become less significant because these create higher Reynolds number at the test section inlet.

The discussion above identifies 11 variables that would potentially need to be varied to fully characterize the cause of the fluid instabilities: pressure, bulk fluid temperature, film temperature, wall temperature. heat flux, test section length, diameter, mass flow rate, volume flow rate, velocity, and inlet temperature. However, as already mentioned, not all of the variables can be independently controlled, as there are significant dependencies among them. After careful consideration of previous experiments and suggested causes of instabilities, the list of potential control variables was narrowed down to five: (1) test section length, (2) test section inside diameter, (3) mass flow rate, (4) inlet fluid temperature, and (5) heat flux. The values, or levels, of these five variables determined the second set of 'control' variables, which will be called psuedo-control variables: (1) bulk fluid temperature profile (as a function of axial length in the test section), (2) film temperature profile, and (3) coolant-side wall temperature profile.

The test matrix of experiments run followed a statistical design of experiments (DOE) strategy known as a partially replicated, half-fraction of a $2^{5}$ full factorial, or a $2^{5-1}$ fractional factorial. This DOE permitted the efficient quantification of the linear and interactive effects of five experimental factors. Each of the five factors were limited to just two levels, a low and a high value. The five factors and their corresponding levels investigated in this study are listed in table 1.

Table 2 lists the 32 tests required for a $2^{5}$ full factorial design. However, only one-half of this test matrix, or 16 unique experiments, are required in a $2^{5-1}$ fractional factorial design. These 16 are highlighted in the table. They permit the estimation of an intercept. five linear, and 10 two-way interactive effects or coefficients. It should be noted that the other half of the test matrix could have been tested with equivalent results. Several, but not all of the 16 unique experiments were repeated in order to quantify experimental reproducibility. These repeats were used in judging the significance of the various model terms.

The selected combination of variables will result in several types of film temperature profiles. These profiles include film temperature less than critical temperature throughout the test section, film temperature greater than critical temperature at some point in the test section, and film temperature greater than critical temperature throughout the test section. In addition, the high and low combinations for the five control variables were selected 
TABLE 1. - HIGH AND LOW VALUES OF CONTROL VARIABLES.

\begin{tabular}{|l|c|c|c|c|}
\hline \multicolumn{1}{|c|}{ Control variable } & Symbol & Units & Low value & High value \\
\hline $\mathrm{X}_{1}:$ test section heated length & $\mathrm{L}$ & inch & 14 & 20 \\
\hline $\mathrm{X}_{2}:$ inside diameter & $\mathrm{D}_{\mathrm{i}}$ & inch & 0.1175 & 0.180 \\
\hline $\mathrm{X}_{3}:$ mass flow rate & $\mathrm{m}$ & $\mathrm{lbm} / \mathrm{s}$ & $0.07 \mathrm{I}$ & 0.142 \\
\hline $\mathrm{X}_{4}:$ inlet fluid temperature & $\mathrm{T}_{\mathrm{j}}$ & ${ }^{\circ} \mathrm{F}$ & 60 & 200 \\
\hline $\mathrm{X}_{5}:$ heat flux & $\mathrm{Q}$ & $\mathrm{BTU} / \mathrm{in.}{ }^{2} / \mathrm{s}$ & 2 & 4 \\
\hline
\end{tabular}

TABLE 2.-FULL TEST MATRIX FOR FIVE VARIABLES AT TWO LEVELS EACH.

\begin{tabular}{|c|c|c|c|c|c|}
\hline \multirow{2}{*}{} & \multicolumn{5}{c|}{ Control Variables } \\
\cline { 2 - 6 } & $\mathrm{X}_{1}$ & $\mathrm{X}_{2}$ & $\mathrm{X}_{3}$ & $\mathrm{X}_{4}$ & $\mathrm{X}_{5}$ \\
\hline $\begin{array}{c}\text { Test matrix } \\
\text { number }\end{array}$ & $\begin{array}{c}\mathrm{L} . \\
\text { in. }\end{array}$ & $\begin{array}{c}\mathrm{D}_{\mathrm{i}} . \\
\text { in. }\end{array}$ & $\begin{array}{c}\mathrm{m} . \\
\mathrm{lbm} / \mathrm{s}\end{array}$ & $\begin{array}{c}\mathrm{T}_{\mathrm{j}} \\
{ }_{\mathrm{F}}\end{array}$ & $\begin{array}{c}\mathrm{Q}, \\
\text { BTU/in. }^{2} / \mathrm{s}\end{array}$ \\
\hline 1 & 14 & .180 & .0707 & 60 & 2 \\
\hline 2 & 14 & .180 & .0707 & 60 & 4 \\
\hline 3 & 14 & .180 & .0707 & 200 & 2 \\
\hline 4 & 14 & .180 & .0707 & 200 & 4 \\
\hline
\end{tabular}

\begin{tabular}{|c|c|c|c|c|c|}
\hline 5 & 14 & .180 & .1414 & 60 & 2 \\
\hline 6 & 14 & .180 & .1414 & 60 & 4 \\
\hline 7 & 14 & .180 & .1414 & 200 & 2 \\
\hline 8 & 14 & .180 & .1414 & 200 & 4 \\
\hline
\end{tabular}

\begin{tabular}{|c|c|c|c|c|c|}
\hline 9 & 14 & 1175 & .0707 & 60 & 2 \\
\hline 10 & 14 & .1175 & .0707 & 60 & 4 \\
\hline 11 & 14 & .1175 & .0707 & 200 & 2 \\
\hline 12 & 14 & .1175 & .0707 & 200 & 4 \\
\hline
\end{tabular}

\begin{tabular}{|c|c|c|c|c|c|}
\hline 13 & 14 & .1175 & .1414 & 60 & 2 \\
\hline 14 & 14 & 1175 & .1414 & 60 & 4 \\
\hline 15 & 14 & .1175 & .1414 & 200 & 2 \\
\hline 16 & 14 & .1175 & .1414 & 200 & 4 \\
\hline
\end{tabular}

\begin{tabular}{|c|c|c|c|c|c|}
\hline 17 & 20 & 180 & .0707 & 60 & 2 \\
\hline 18 & 20 & .180 & .0707 & 60 & 4 \\
\hline 19 & 20 & .180 & .0707 & 200 & 2 \\
\hline 20 & 20 & .180 & .0707 & 200 & 4 \\
\hline
\end{tabular}

\begin{tabular}{|c|c|c|c|c|c|}
\hline 21 & 20 & .180 & .1414 & 60 & 2 \\
\hline 22 & 20 & 180 & 1414 & 60 & 4 \\
\hline 23 & 20 & .180 & .1414 & 200 & 2 \\
\hline 24 & 20 & .180 & .1414 & 200 & 4 \\
\hline
\end{tabular}

\begin{tabular}{|c|c|c|c|c|c|}
\hline 25 & 20 & .1175 & .0707 & 60 & 2 \\
\hline 26 & 20 & .1175 & .0707 & 60 & 4 \\
\hline 27 & 20 & .1175 & .0707 & 200 & 2 \\
\hline 28 & 20 & .1175 & .0707 & 200 & 4 \\
\hline
\end{tabular}

\begin{tabular}{|c|c|c|c|c|c|}
\hline 29 & 20 & .1175 & .1414 & 60 & 2 \\
\hline 30 & 20 & .1175 & .1414 & 60 & 4 \\
\hline 31 & 20 & .1175 & .1414 & 200 & 2 \\
\hline 32 & 20 & .1175 & .1414 & 200 & 4 \\
\hline
\end{tabular}

to create similar film temperature profiles with different combinations of control variables.

\section{Buoyancy Forces}

To determine if buoyancy forces were significant, the definition of Grashof number and basis of comparing it to
Reynolds number were taken from reference 14. For vertical flow, the Grashof number, which is the ratio of buoyancy to viscous forces, is based on the integrated density, and is defined here as:

$$
\overline{G r_{b}}=\frac{\rho_{f}^{2}\left(\rho_{b}-\bar{\rho}\right) d^{3} g}{\mu_{f}^{2} \rho_{b}}
$$

with

$$
\bar{\rho}=\left(T_{w}-T_{b}\right)^{-1} \int_{T_{b}}^{T_{w}} \rho d T \approx \rho_{f}
$$

where

$\begin{array}{ll}\rho & \text { density } \\ \mu & \text { viscosity } \\ g & \text { gravitational constant } \\ T & \text { temperature } \\ d & \text { inside diameter }\end{array}$

and the subscripts $w, b$, and $f$ stand for wall, bulk, and film, respectively. Reynolds number is the ratio of inertia to viscous forces and is defined here as:

$$
\operatorname{Re}_{b}=\frac{4 \dot{m}}{\pi d \mu_{b}}
$$

where $\dot{m}=$ mass flow rate.

Buoyancy forces are considered to be significant in vertical flow if: ${ }^{14}$

$$
\frac{\overline{G r_{b}}}{\operatorname{Re}^{2.7}}>1 * 10^{-5}
$$

The value of Reynolds number can be increased to make buoyancy forces less significant by either an increase in mass flow rate or an increase in fluid temperature (thereby decreasing viscosity). Although a decrease in viscosity would also increase Grashof number, this is offset by the corresponding decrease in density with increased temperature. In the test matrix selected, buoyancy 
forces are significant at the test section inlet for all cases with the lowest velocity and insignificant for all cases with the highest velocity. However, for the cases with a medium velocity, the significance of the buoyancy forces was affected by controlling the fuel inlet temperature. At an inlet temperature of $60^{\circ} \mathrm{F}$ buoyancy forces were significant, but at $200^{\circ} \mathrm{F}$ they were not. Because increasing the fuel temperature increases Reynolds number, buoyancy forces became insignificant at some point in the test section for most of the cases.

\section{Test Facility, Hardware, and Procedures}

The tests were conducted in the NASA Glenn Research Center Heated Tube Facility. The combustible liquids system was used for these tests. The entire facility is described in detail in reference 15 .

\section{Facility}

A simplified schematic of the combustible liquids system is shown in figure 2 . The test section was mounted vertically within a vacuum chamber that was kept below $0.01 \mathrm{psi}(69 \mathrm{~Pa})$. The vacuum environment minimized heat losses due to convection and provided a measure of safety in the event of a fuel leak. The test section was heated electrically by passing a current through the tube. Four direct current power supplies were available, each capable of $1500 \mathrm{~A}$ and $80 \mathrm{~V}$. The fuel was stored in a supply tank rated for pressures up to $1650 \mathrm{psi}$. The driving force was provided by pressurizing the supply tank with gaseous nitrogen. Separate valves were used for flow rate and test section back pressure control. A Coriolis-force flow meter was used to provide accurate flow measurement of the JP-7 fuel. The coolant temperature and pressure were measured at the inlet and exit of the test section by thermocouples and pressure transducers, and heat input was determined by recording the voltage and current applied to the test section. These facility and research instrumentation data were recorded on the facility's data system at a rate of one sample of each signal per second.

Several additions were made to the facility for this test program:

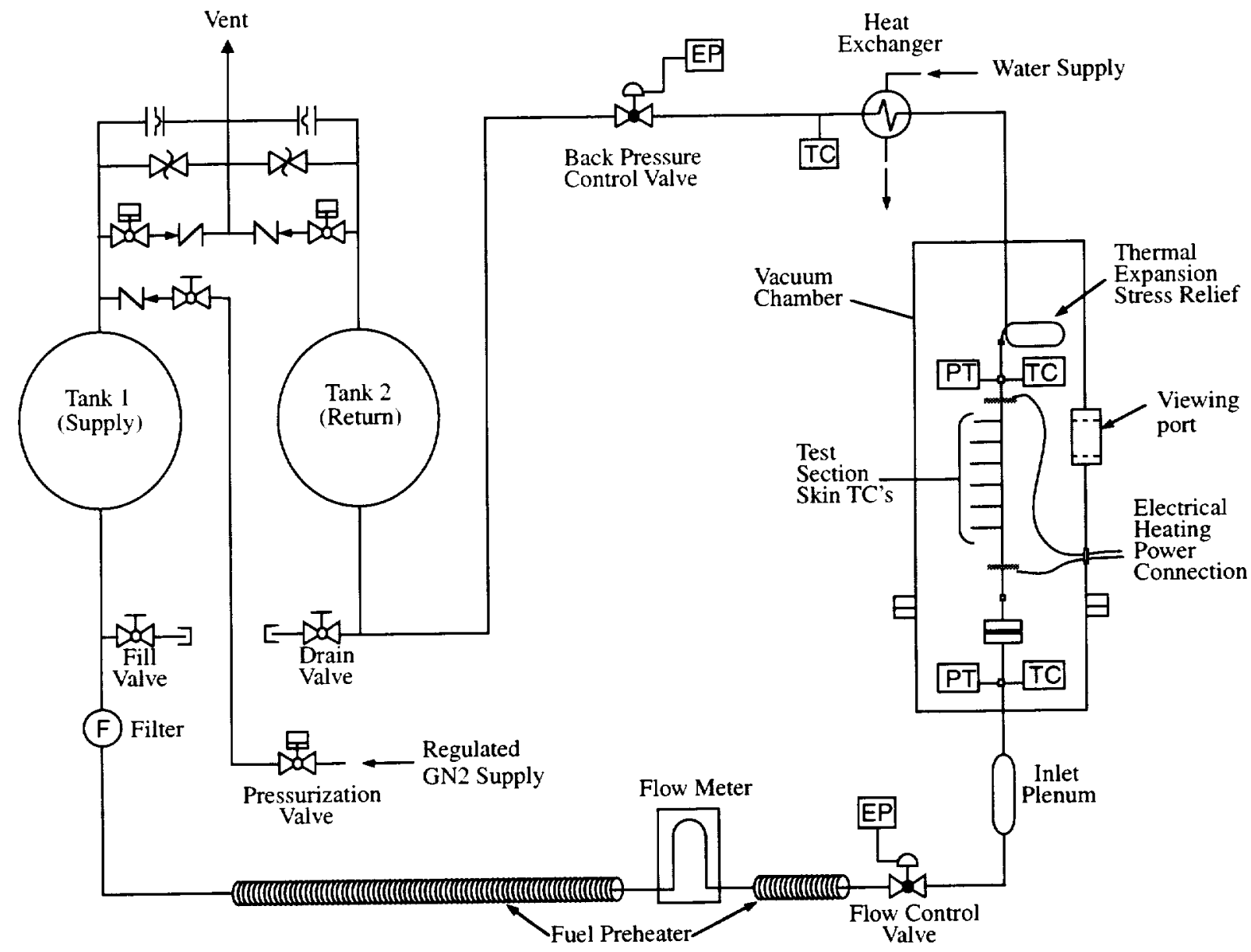

Figure 2.-Schematic of combustible liquid flow system in the NASA Glenn Research Center Heated Tube Facility. 
- A fuel preheater was added to provide the ability to raise the inlet temperature of the fuel. This was accomplished by wrapping $\sim 40 \mathrm{ft}$ of the fuel inlet line with resistance heaters. By maintaining the surface temperature of the inlet line at $\sim 250^{\circ} \mathrm{F}$, the inlet fuel temperature could be increased to $200^{\circ} \mathrm{F}$.

- Two high frequency piezoresistive pressure transducers were added to measure the pressure fluctuations at the test section inlet and outlet. These transducers had a minimum resonance frequency of $20000 \mathrm{~Hz}$, and their output signals were recorded on a FM tape recorder with an analog bandwidth of $20000 \mathrm{~Hz}$ for each signal channel. These dynamic signals were later digitized for analysis. The high-frequency pressure transducers were used as the primary response data for indication of the presence of fluid instabilities.

- Two viewing ports were added to the vacuum chamber can to allow for remote viewing of the test section. If the test section was at high temperature when instabilities occurred, low frequency wall temperature fluctuations were visible as a change in the thermal signature as viewed by the video camera.

\section{Test Hardware}

The test sections for these tests were fabricated from Haynes 230 tubing with a wall thickness of 0.035 in. and an outside diameter of either 0.25 or $0.1875 \mathrm{in}$. The total length of the Haynes tube was either 27 or 29 in., with either 14 or $20 \mathrm{in}$. of heated length. Copper disks of $0.5 \mathrm{in}$. thickness were brazed to the tube and provided convenient electrical connections for test section heating.

The test sections were instrumented with type $K$ thermocouples which were spot welded directly to the outer surface. The thermocouples were located at 1.2,5. 9,12 , and 13 in. from the start of the heated section for the 14-in. test section (fig. 3), and at 1, 2, 5, 10,14, 18, and 19 in. for the 20-in. test section. Each test section was calibrated in a water-cooled calibration rig prior to testing in order to check and correct for induced temperature bias error in the thermocouples caused by the voltage across the test section. Reference 16 discusses this error potential and the method used to correct for it if present.

\section{Coolant Properties}

Thermophysical properties of $n$-dodecane $\left(\mathrm{C}_{12} \mathrm{H}_{26}\right)$ were used to model the JP-7 fuel. ${ }^{17}$ The $\mathrm{n}$-dodecane properties were obtained from the National Institute of Standards and Technology reference database. ${ }^{18}$ Critical conditions were assumed to be $260 \mathrm{psi}$ and $760{ }^{\circ} \mathrm{F}$ $\left(1.8 \mathrm{MPa}\right.$ and $\left.404{ }^{\circ} \mathrm{C}\right)$.

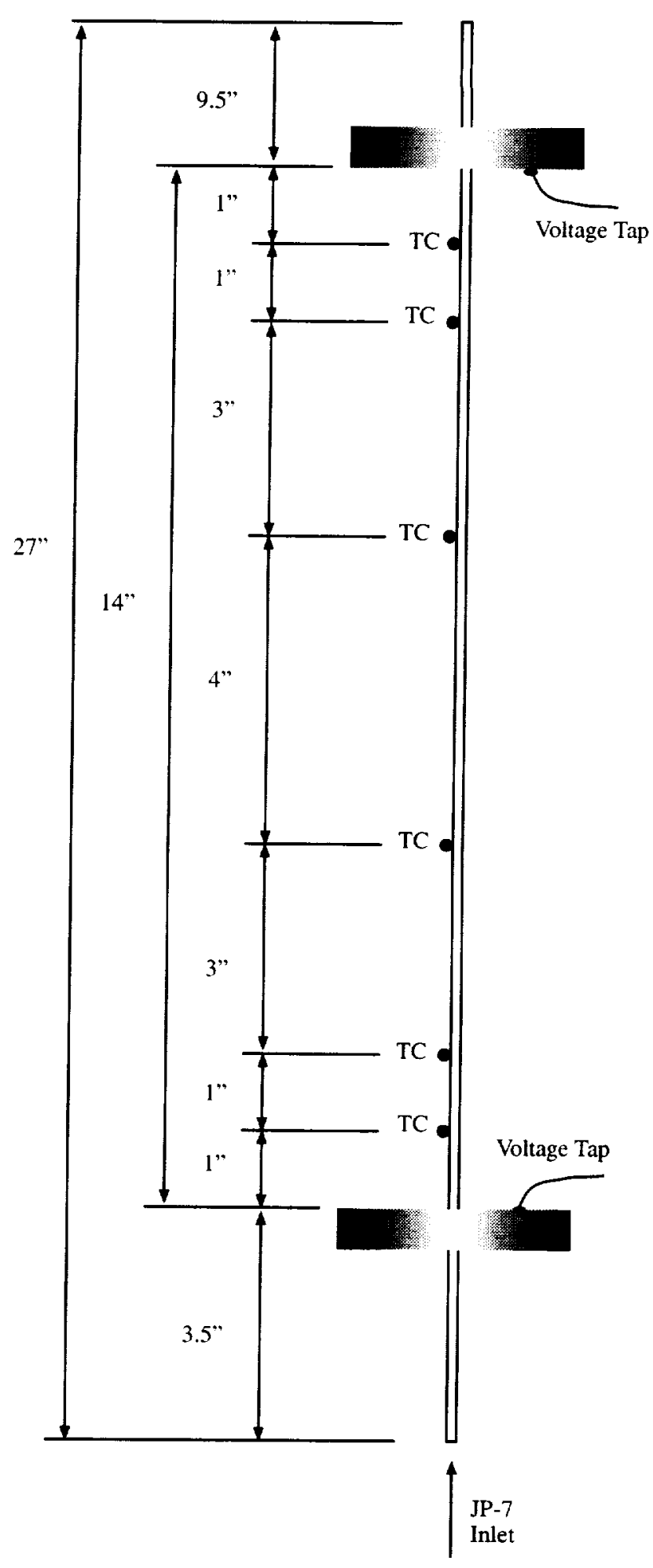

Figure 3.-Schematic of 14 inch test section hardware and instrumentation (TC - thermocouple). 


\section{Procedure}

A typical test run procedure started by filling the supply tank with JP-7 and pressurizing the ullage with gaseous nitrogen. The empty return tank was vented to the atmosphere. The coolant flow was stabilized at flow rate and back pressure ( $1000 \mathrm{psi}$ ) set points prior to turning on the electrical heating power supplies. The power was increased in steps until the target heat flux was achieved. Some of the tests were stopped at a heat flux lower than the target value when the instabilities caused large wall temperature fluctuations that threatened to cause test section failure. Figure 4 shows the profiles of fluid outlet temperature, heat flux, and coolant-side wall temperature versus test time for a representative test. This test was unstable, and the effects of the instabilities can be seen in the wall temperature fluctuations while heat flux was held constant during the last $45 \mathrm{sec}$ of the test.

Coolant side wall temperature was calculated from the hot side wall thermocouples using two methods. The first method was an iterative procedure that calculated local heat flux, electrical resistivity, and thermal conductivity for each portion of the test section containing a thermocouple. The second method used direct radial conduction assuming equal power distribution throughout the test section. Coolant wall temperatures calculated from the two methods were within $1^{\circ}$ of each other. Typical temperature deltas across the wall of the test sections were between 100 and $150^{\circ} \mathrm{F}$ at the low heat flux and 200 and $250^{\circ} \mathrm{F}$ at the high heat flux.

\section{Results and Discussion}

Due to experimental limitations and constraints in the factors $X_{3}=$ mass flow rate, $X_{4}=$ inlet temperature, and $\mathrm{X}_{5}=$ heat flux, it was impossible to achieve exactly the levels called for in the DOE. Table 3 shows the results from the actual experimental runs. Test matrix number identifies the planned target conditions from table 2 . Rdg number is the test reading number and is included to delineate between repeated tests of the same test matrix. In order to assess system reproducibility and thus judge significance of investigated effects, test matrix numbers 2 ,

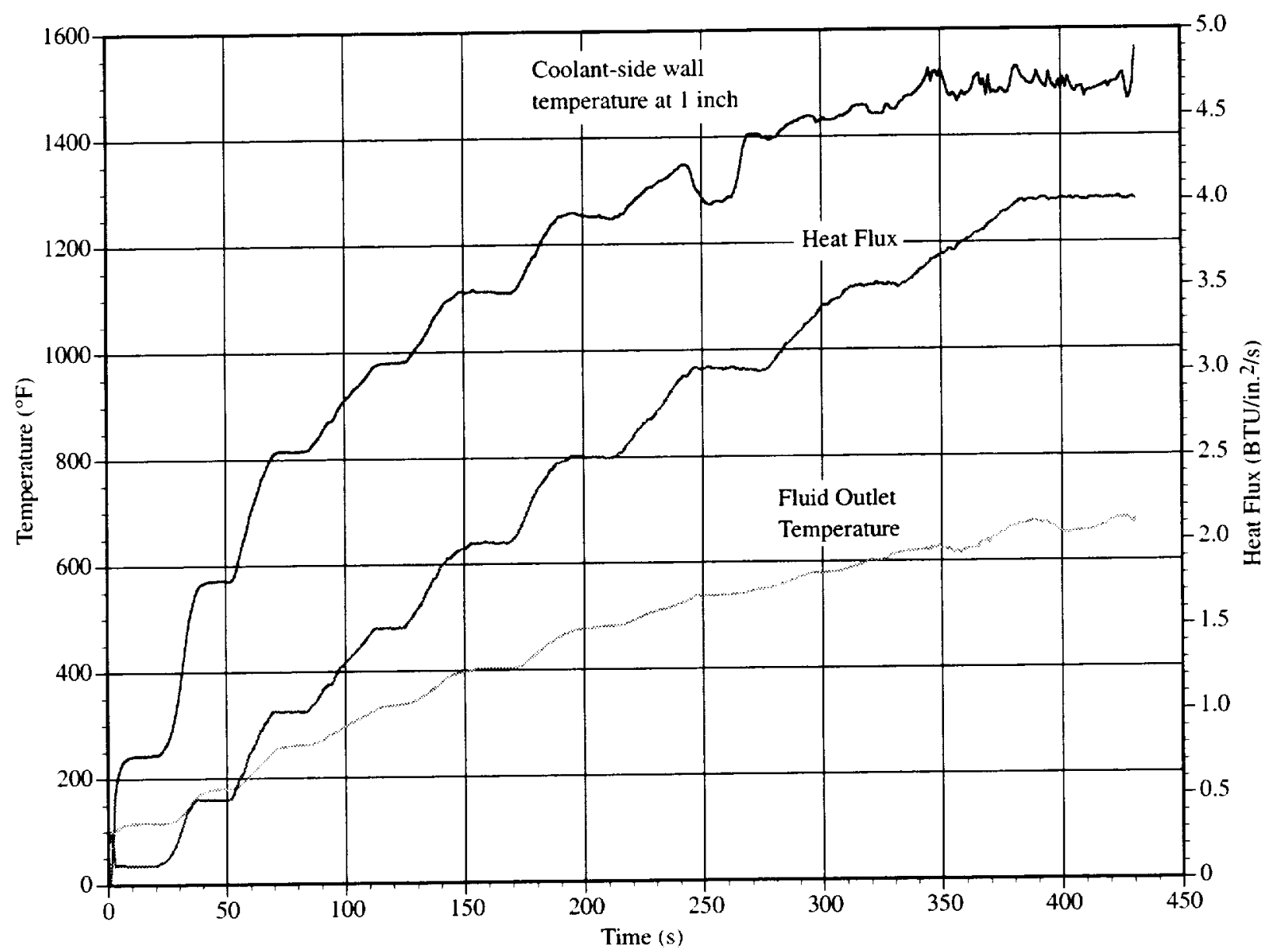

Figure 4.-Typical profile of wall temperature, heat flux, and fuel outlet temperature, test matrix 2, reading 81. 


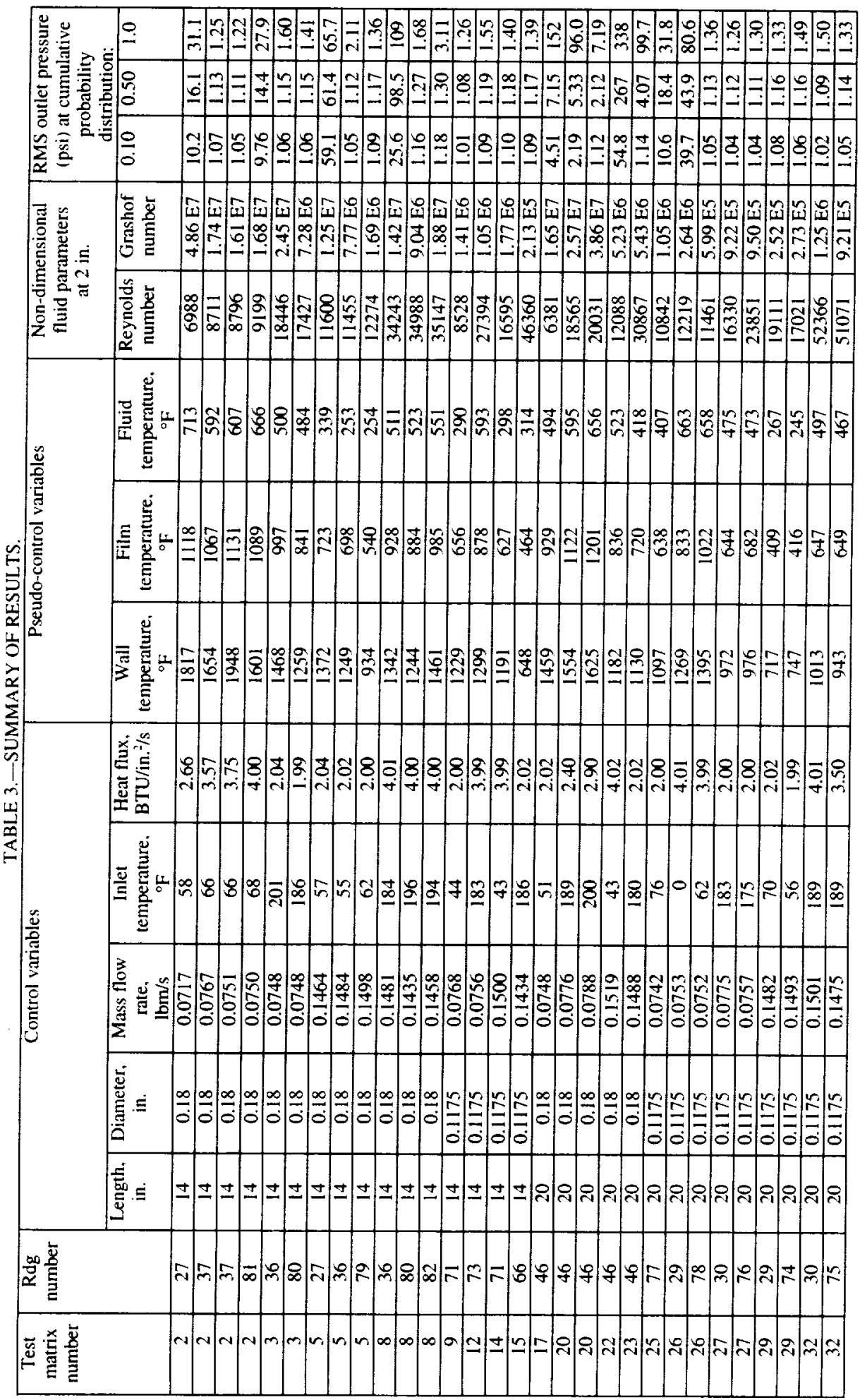


$3,5,8,20,26,27,29$, and 32 were repeated one or more times. Notice that the experimental condition with low mass flow rate and the other four variables at their high levels was not attainable (test matrix 20). Instead, a lower level of $X_{5}=$ Heat Flux was used. Notice also that an "extra" experiment was run at the condition $\mathrm{X}_{1}=$ length at the high value of $20 \mathrm{in}$. and all other $X_{i}$ at their low values. This is the experiment labeled test matrix 25 in table 3 . All values for the control variables, temperatures, and fluid parameters listed in the table are an average value during the period of the test at which the heat flux was at its target value (or the maximum attainable).

The maximum wall temperature in the table is the coolant-side wall temperature calculated from the thermocouples on the outside of the test section. The location of the maximum temperature varied. For the majority of the tests, the hottest portion of the wall was near the beginning of the test section (measured by either the $1^{\text {st }}$ or $2^{\text {nd }}$ thermocouple). However, for about one third of the tests, the hottest portion of the test section was in the second half of the heated length. The maximum fluid temperature listed in the table is the measured coolant outlet temperature. Film temperature is the average of wall temperature and fluid temperature, and the maximum film temperature listed is the value where this was a maximum (usually near the beginning of the test section).

\section{Reduction of High-Speed Data}

Figure 5 shows the raw data from the outlet pressure transducer for some representative tests. Nominal pressure for all cases was $1000 \mathrm{psi}$. An unstable test condition is shown in figure $5(\mathrm{a})$, where the outlet pressure oscillations for test matrix 5 (reading 27) are consistent and large during the entire time at the target condition. The maximum peak to peak fluctuation was $\sim 260 \mathrm{psi}$, and the predominant frequency was about $660 \mathrm{~Hz}$ (and several harmonics). For some unstable conditions, there were brief periods of weaker pressure oscillations in the midst of strong instabilities. This can be seen in figure 5(b) (test matrix 22, reading 46 ), where there are $-3 \mathrm{sec}$ of weaker oscillations during the $15 \mathrm{sec}$ total time at the target heat flux. However, since this test provided the strongest oscillations, with a maximum peak to peak of $1000 \mathrm{psi}$, even the relatively weaker period had a peak to peak of 280 psi. During the strong oscillations, the predominant frequency was around $1910 \mathrm{~Hz}$; figure 5 (c) shows $\sim 10$ cycles at $10 \mathrm{sec}$ into the test. During the weaker oscillations, the frequency of 1910 $\mathrm{Hz}$ was strong, but there were also additional nonharmonic frequencies of 2150 and $2350 \mathrm{~Hz}$. Figure 5(d) (test matrix 23 , reading 46) shows another unstable condition. This one has a pattern of pulsating periods of instabilities. Typical peak to peak during the instabilities was $350 \mathrm{psi}$, with several overlapping frequencies between 575 and $3800 \mathrm{~Hz}$. In this case, the periods in between the strong oscillations had near zero peak to peak fluctuation and therefore no identifiable frequency. Figure 5 (e) (test matrix 25 , reading 77 ) has a similar pattern of pulsating periods of instabilities. In this case, the periods of stronger oscillations occurred closer together with a peak to peak of $\sim 100 \mathrm{psi}$; the periods of weaker oscillations were not zero, but had a peak to peak of $\sim 40$ psi. Both periods had a similar frequency around $585 \mathrm{~Hz}$. Figure 5(f) (test matrix 2 , reading 81 ) is a combination of long periods of consistent, strong oscillations and periods of pulsating oscillations. Finally, figure $5(\mathrm{~g})$ (test matrix 29 , reading 74 ) shows the outlet pressure oscillations for a typical stable test condition. In this case, peak to peak oscillations were on the order of $10 \mathrm{psi}$.

The root mean square (RMS) magnitude of the outlet pressure oscillation was used as the response variable and primary indicator of whether a condition was stable or unstable. The value of the RMS is an indicator of both the magnitude and the shape of the pressure fluctuations and is proportional to the square root of the total area under the squared pressure trace. The RMS waveform was chosen because the mean square signal is proportional to the energy which the oscillations of coolant pressure can deliver to the test section, and the RMS is proportional to the instantaneous outlet pressure amplitude. It is more appropriate, therefore, to use the RMS rather than the peak values to measure the effect of an irregular (nonsinusoidal) waveform.

The last three columns in table 3 list the root mean square (RMS) magnitude of the outlet pressure oscillation for cumulative probability distribution values of 10,50 , and 100 percent. In the first row of the table, for example. the oscillations of outlet pressure were less than 10.2 psi RMS 10 percent of the time, were less than 16.1 psi RMS 50 percent of the time, and were always less than the maximum of $31.1 \mathrm{psi}$ RMS. The values in the last three columns of the table provide information about the magnitude and duration of the generally intermittent periods of oscillating outlet pressure during a contiguous time interval manually selected when all control variables were at (or near) their target values. Although this contiguous time interval was short ( 1 to $4 \mathrm{sec}$ ) for a few tests, it was between 10 and $55 \mathrm{sec}$ long for most of the tests.

The RMS outlet pressure values listed in table 3 were calculated using the following procedure. First the RMS pressure waveform as a function of time was calculated from the dynamic outlet pressure data recorded on analog FM magnetic tape. The outlet pressure data from the instrumentation tape were played back with the full analog bandwidth of $20000 \mathrm{~Hz}$ (i.e., cycles/sec). An 8-pole elliptic low pass analog filter was then applied to the data with a cutoff frequency of $4000 \mathrm{~Hz}$ and a $130 \mathrm{~dB} /$ octave initial rolloff to provide antialiasing by at least $80 \mathrm{~dB}$. That conditioned signal was then digitized by a 

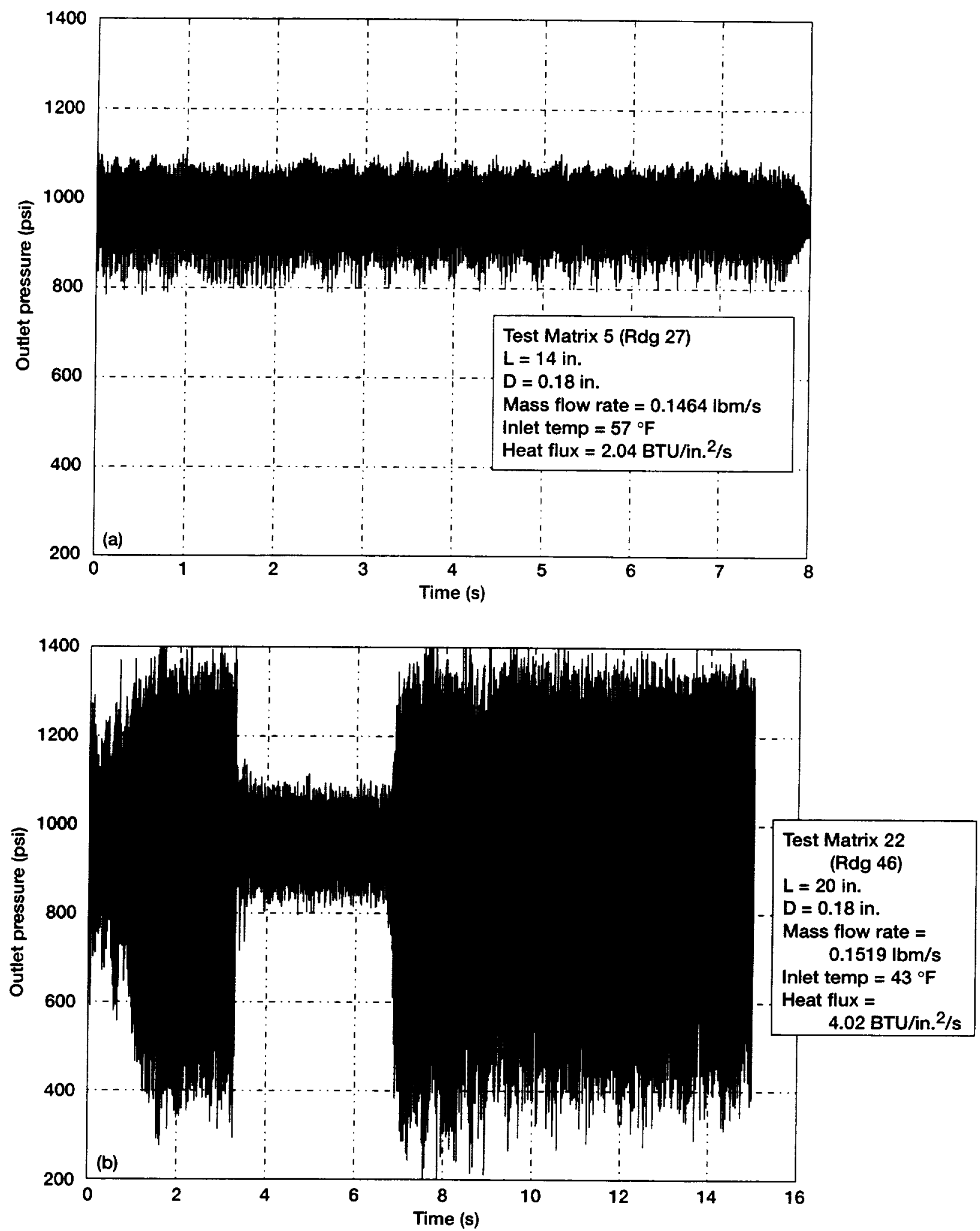

Figure 5.-Raw outlet pressure data for representative tests. (a) Unstable test, maximum peak-to-peak approximately 260 psi. (b) Unstable test with two distinct ranges, maximum peak-to-peak approximately 1000 psi. (c) Expanded portion of fig. 5 b data showing approximate frequency of $1900 \mathrm{~Hz}$. (d) Unstable test with pulsating instabilities. (e) Unstable test with pulsating instabilities (faster repeat rate than in fig. 5d). (f) Unstable test with irregular pattern. (g) Stable test. 

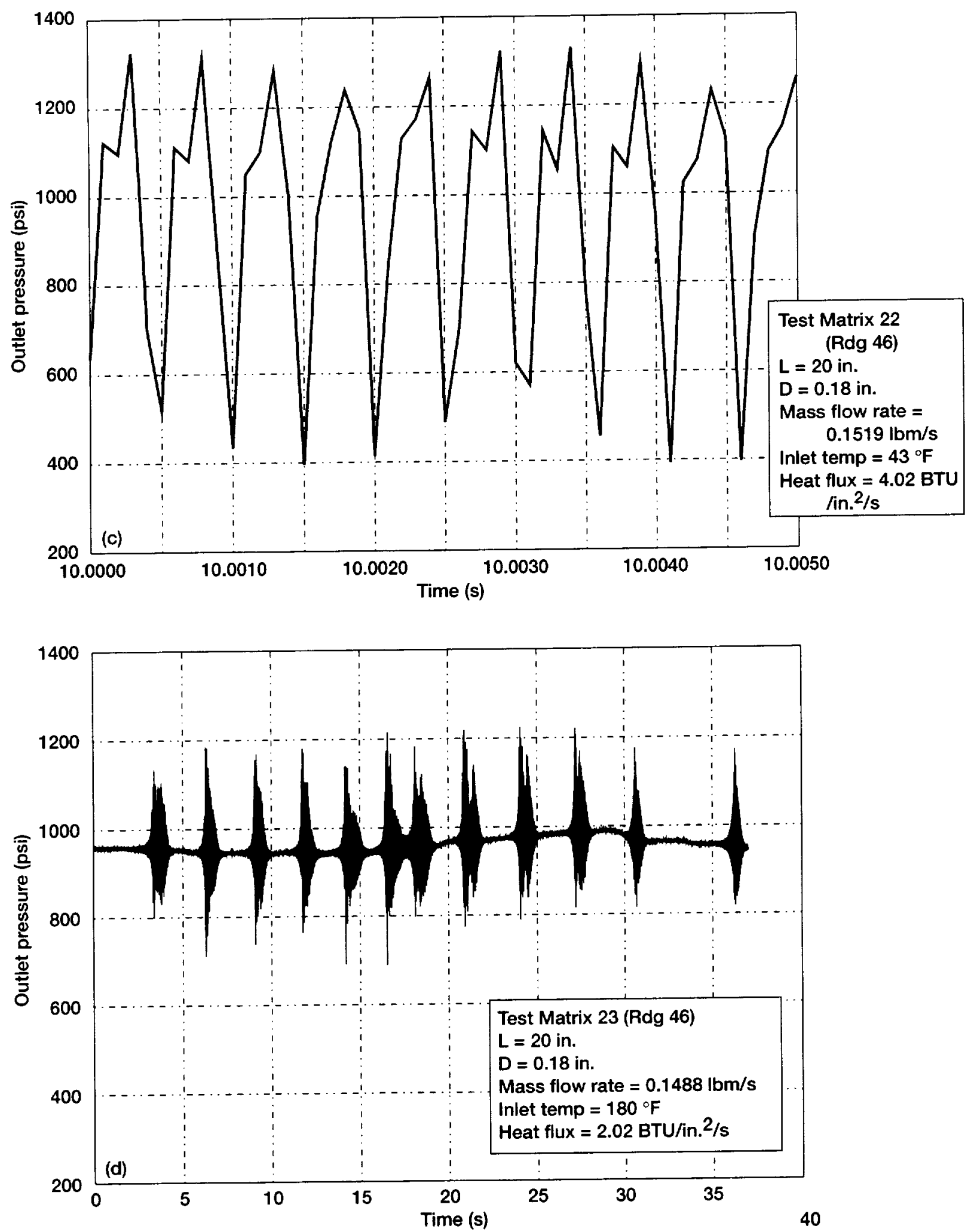

Figure 5.-Continued. (c) Expanded portion of fig. $5 \mathrm{~b}$ data showing approximate frequency of $1900 \mathrm{~Hz}$.

(d) Unstable test with pulsating instabilities. 

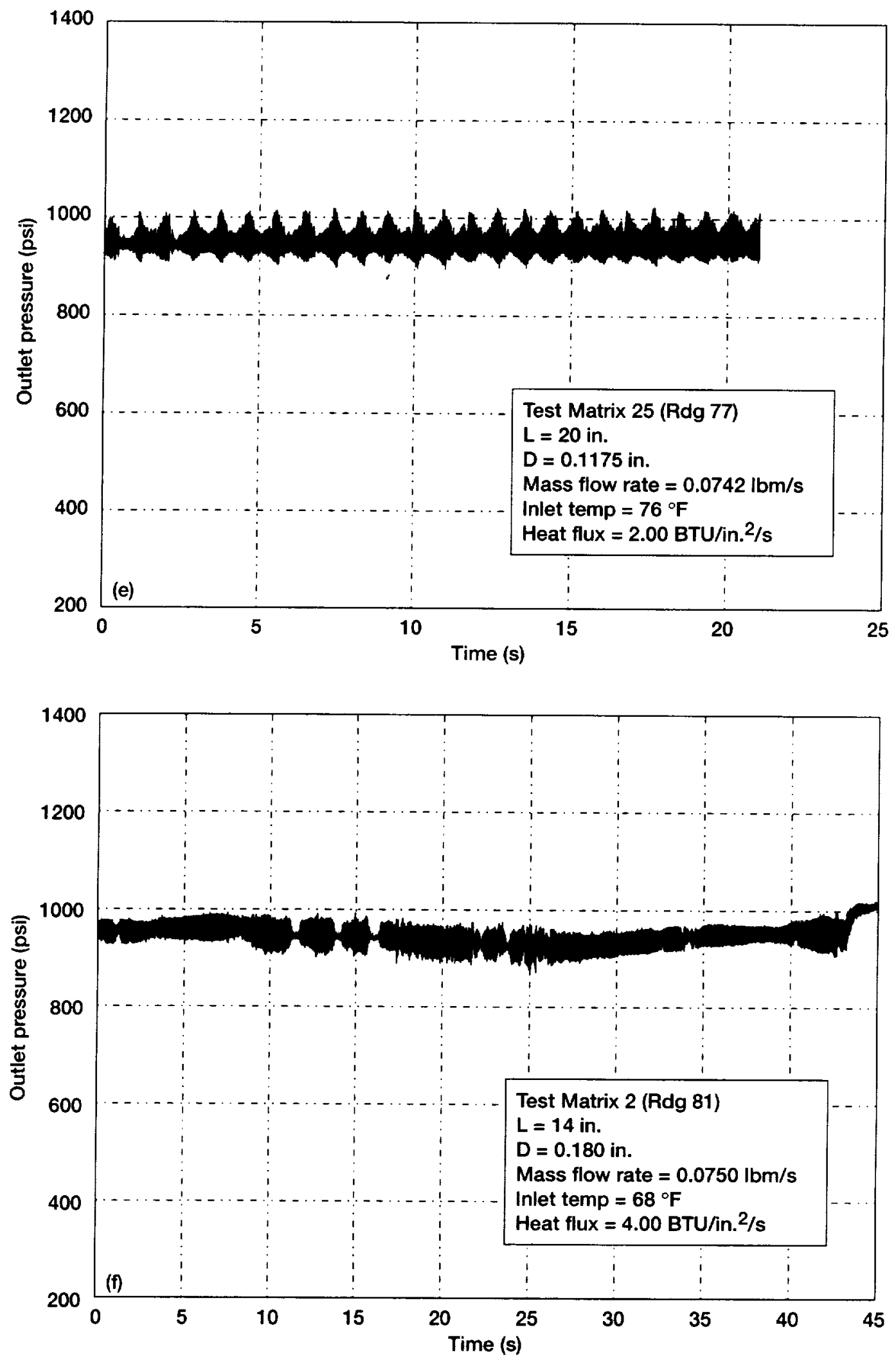

Figure 5.-Continued. (e) Unstable test with pulsating instabilities (faster repeat rate than in fig. 5d). (f) Unstable test with irregular pattern. 


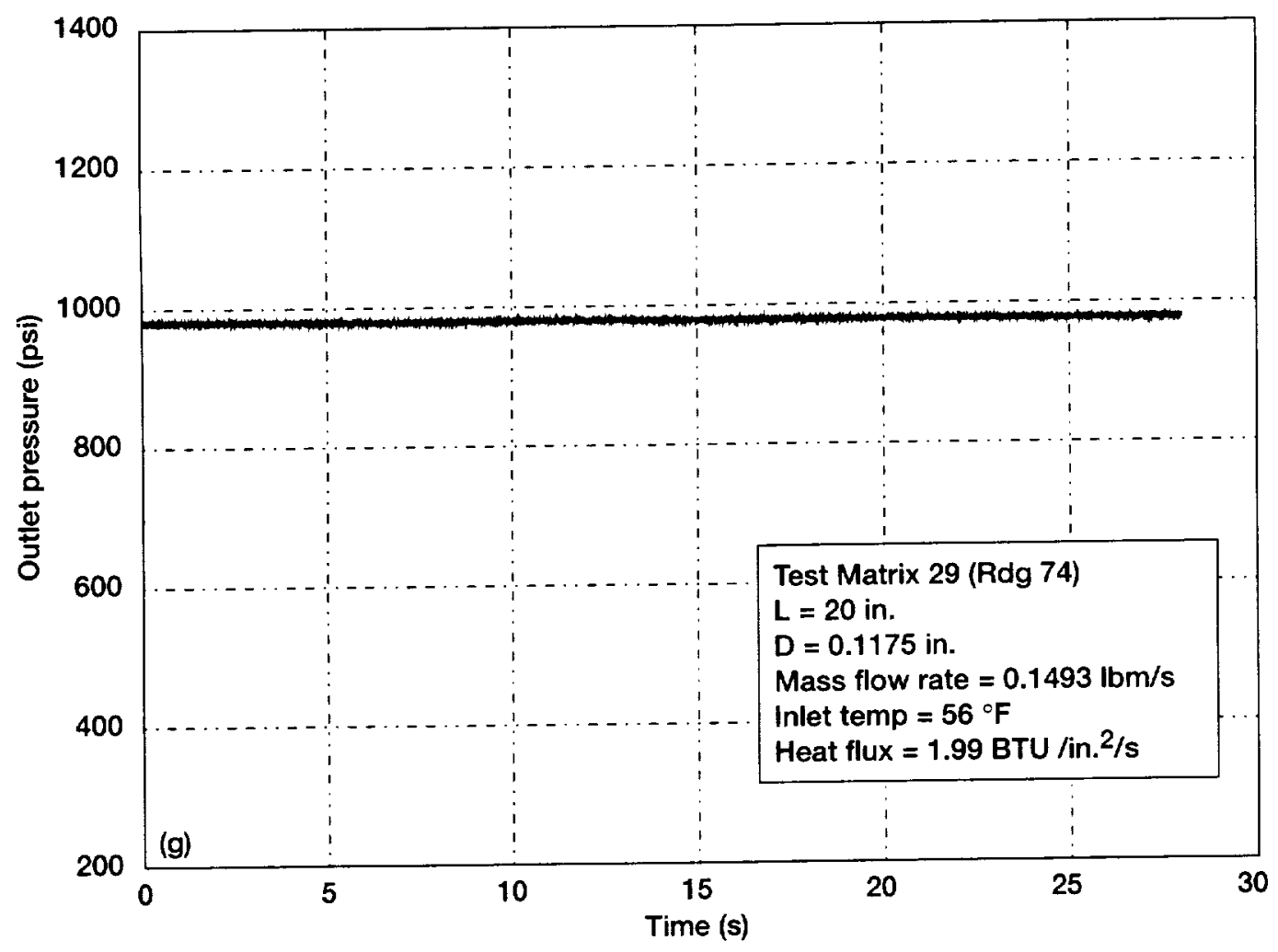

Figure 5.-Concluded. (g) Stable test.

16-bit analog-to-digital converter at a rate of 10000 samples/sec. A finite impulse response (FIR, or "moving average") high pass digital filter with a cutoff frequency of $200 \mathrm{~Hz}$ and a window width of 1024 samples (i.e., computing the output sample at each time $t$ by calculating a weighted average of the input samples in a window from time $t-0.0512 \mathrm{sec}$ to $t+0.0512 \mathrm{sec}$ ) was used to remove the gradually changing mean value from the data. The cutoff frequency of $200 \mathrm{~Hz}$ was chosen to preserve all significant pressure oscillations while eliminating low frequency mean pressure offsets and any electrical noise at the first three harmonics of the $60 \mathrm{~Hz}$ power. During periods of instability, the filtered pressure waveform typically looked like a distorted sinusoid with gradual variations in peak amplitude as a function of time. For a few tests there were bursts of high amplitude oscillations (see fig. 5). Changes in the overall magnitude of this waveform were represented by the square root of the running mean of the squares (i.e., the RMS) of the instantaneous data values. This RMS waveform was computed by squaring each high-pass-filtered data sample, applying a finite impulse response low pass digital filter with a cutoff frequency of $10 \mathrm{~Hz}$ and a window width of 2048 samples (i.e., $0.2048 \mathrm{sec}$ ), and then calculating the square root of each resulting low pass filtered sample. The
RMS waveform varied rather slowly (less than about 10 cycles/sec), essentially following a smoothed envelope above the distorted sinusoidal waveform.

After the RMS pressure waveform as a function of time was calculated, the cumulative probability distribution could be determined. The initial $0.1 \mathrm{sec}$ and the final $0.1 \mathrm{sec}$ of the RMS waveform were always discarded to eliminate end effects of the digital filtering. The pressure range from the minimum to the maximum peak values of the truncated waveform was then divided into 200 equal "bins," and the probability density function of the truncated RMS waveform was computed by counting the number of samples in each bin and dividing by the total number of samples in the waveform. The cumulative probability distribution, $F(p)$, of the truncated RMS waveform was then determined by computing the integral of the discrete probability density function. where $F(p)$ is the probability that the truncated RMS pressure waveform is less than $p$. Therefore, $F(p)$ increases monotonically from 0 to 100 percent as $p$ increases from the minimum to the maximum pressure of the truncated RMS waveform. The values in the last three columns of the table are the interpolated RMS pressures $p_{0.1}, p_{0.5}$, and $p_{1.0}$ where $F\left(p_{0.1}\right)=10$ percent, $F\left(p_{0.5}\right)=50$ percent, and $F\left(p_{1.0}\right)=100$ percent. 
Analysis of Data from Actual DOE

The statistical analysis of the data was performed using $\mathrm{Y}=$ maximum RMS outlet pressure $\left(p_{1.0}\right)$ as the response variable (i.e., the last column in table 3 ). The first step in the analysis of the data was to conduct an analysis of the "repeat" experiments. Notice from table 3 that some of the "repeats" were too far off to be used as estimates of the system reproducibility. Therefore, it was necessary to first define which of the experiments were close enough in the X space to truly call them "repeats." For example, the experimental condition designated test matrix 2 had one very different repeat with $\mathrm{X}_{5}=$ heat flux at a much lower level of 2.66 (reading 27). The following ad hoc designations were employed, where $X_{i}$ Rep. Range was the range of the $X_{i}$ values over just the "repeats" and $X_{i}$ Total Range was the range of the experimental $X_{i}$ values over all 30 experiments.

"Good" Reps. [ $\left[\left(X_{i}\right.\right.$ Rep. Range $) /\left(X_{i}\right.$ Total Range $\left.)\right]$ $\times 100$ percent $<5$ percent for each $X_{i}$

"Fair" Reps. [( $X_{\mathrm{i}}$ Rep. Range $) /\left(\mathrm{X}_{\mathrm{i}}\right.$ Total Range $\left.)\right]$ $\times 100$ percent $<10$ percent for each $X_{i}$

"Poor" Reps. $\quad\left[\left(\mathrm{X}_{\mathrm{i}}\right.\right.$ Rep. Range $) /\left(\mathrm{X}_{\mathrm{i}}\right.$ Total Range $\left.)\right]$ $\times 100$ percent $<25$ percent for each $X_{i}$

Note that these designations are based on $X$ values only. Once the "repeats" had been identified, then their corresponding $\mathrm{Y}$ response values were analyzed. Table 4 lists just the "repeats" and is, therefore, a subset of the entire actual DOE presented in table 3.
With the various types of "repeats" identified, it was possible to examine the response variable, $\mathrm{Y}=$ maximum RMS outlet pressure $\left(p_{1.0}\right)$, to determine the system reproducibility. Unfortunately, the system reproducibility was less than optimal. For example, notice that in the "repeat" sets of test matrices 5 and 26 (which were designated "Good" or close together in the X space), the response values spanned the very large ranges of $Y=1.36$ to 65.7 for test matrix 5 and $Y=1.36$ to 80.6 for test matrix 26. Then, in the "repeat" set for test matrix 8 (which was designated as "Fair" or fairly close together in the $X$ space), the response values spanned an extremely large range of $Y=1.68$ to 109.4 . With the exception of one very large response value of $Y=338.3$, these "repeat" ranges of response values were approaching the level of the entire range of response values over all 30 experiments. This made the construction of a highly precise, predictive regression model difficult. However, it was possible to identify and quantify trends, both linear and interactive among the five factors studied.

\section{Statistical Model}

As stated previously in the Design of Experiments section, the $2^{5-1}$ fractional factorial DOE permitted the estimation of all five linear effects and all 10 two-way interactive effects among the five variables. A multiple linear regression analysis was conducted using $\mathrm{Y}=$ maximum RMS outlet pressure $\left(p_{1.0}\right)$ as the response and the 15 aforementioned estimable effects as the coefficients on the candidate model terms. Each $X_{i}$ in the model was transformed or "scaled" from its experimental range of values of $X_{\text {iMIN }}$ to $X_{\text {MAAX }}$ to a range of \pm 1 . This

TABLE 4.-IDENTIFICATION AND ANALYSIS OF "REPEAT" EXPERIMENTS

\begin{tabular}{|c|c|c|c|c|c|c|c|}
\hline $\begin{array}{c}\text { Repeat } \\
\text { designation }\end{array}$ & $\begin{array}{c}\text { Test } \\
\text { matrix } \\
\text { number }\end{array}$ & $\begin{array}{c}X_{1} \\
\text { length }\end{array}$ & $\begin{array}{c}\mathrm{X}_{2} \\
\text { diameter }\end{array}$ & $\begin{array}{c}\mathrm{X}_{3} \cdot \\
\text { mass flow rate }\end{array}$ & $\begin{array}{c}X_{4}, \\
\text { inlet temp }\end{array}$ & $\begin{array}{c}X_{5} \\
\text { heat flux }\end{array}$ & $\begin{array}{c}\text { Y, } \\
\text { max RMS } \\
\text { pressure }\end{array}$ \\
\hline \multirow[t]{3}{*}{ "Poor" } & \multirow[t]{3}{*}{2} & \multirow[t]{3}{*}{14} & \multirow[t]{3}{*}{0.1800} & 0.0750 & 68.1 & 4.003 & 27.9020 \\
\hline & & & & 0.0751 & 66.0 & 3.753 & 1.2158 \\
\hline & & & & 0.0767 & 66.2 & 3.571 & 1.2475 \\
\hline \multirow[t]{2}{*}{ "Fair" } & \multirow[t]{2}{*}{3} & \multirow[t]{2}{*}{14} & \multirow[t]{2}{*}{0.1800} & 0.0748 & 185.8 & 1.994 & 1.4129 \\
\hline & & & & 0.0748 & 200.5 & 2.039 & 1.5958 \\
\hline \multirow[t]{3}{*}{ "Good" } & \multirow[t]{3}{*}{5} & \multirow[t]{3}{*}{14} & \multirow[t]{3}{*}{0.1800} & 0.1464 & 57.3 & 2.041 & 65.7320 \\
\hline & & & & 0.1484 & 54.6 & 2.018 & 2.1112 \\
\hline & & & & 0.1498 & 62.0 & 1.999 & 1.3615 \\
\hline \multirow[t]{3}{*}{ "Fair" } & \multirow[t]{3}{*}{8} & \multirow[t]{3}{*}{14} & \multirow[t]{3}{*}{0.1800} & 0.1435 & 196.4 & 3.997 & 1.6819 \\
\hline & & & & 0.1458 & 194.1 & 4.003 & 3.1146 \\
\hline & & & & 0.1481 & 184.1 & 4.006 & 109.370 \\
\hline \multirow[t]{2}{*}{ "Poor" } & \multirow[t]{2}{*}{20} & \multirow[t]{2}{*}{20} & \multirow[t]{2}{*}{0.1800} & 0.0776 & 189.4 & 2.401 & 96.0000 \\
\hline & & & & 0.0788 & 200.2 & 2.898 & 7.1929 \\
\hline \multirow[t]{2}{*}{ "Good" } & \multirow[t]{2}{*}{26} & \multirow[t]{2}{*}{20} & \multirow[t]{2}{*}{0.1175} & 0.0752 & 62.0 & 3.990 & 1.3577 \\
\hline & & & & 0.0753 & 70.1 & 4.013 & 80.5880 \\
\hline \multirow[t]{2}{*}{ "Good" } & \multirow[t]{2}{*}{27} & \multirow[t]{2}{*}{20} & \multirow[t]{2}{*}{0.1175} & 0.0757 & 175.2 & 1.998 & 1.2970 \\
\hline & & & & 0.0775 & 182.9 & 2.002 & 1.2632 \\
\hline \multirow[t]{2}{*}{ "Fair" } & \multirow[t]{2}{*}{29} & \multirow[t]{2}{*}{20} & \multirow[t]{2}{*}{0.1175} & 0.1482 & 70.1 & 2.021 & 1.3251 \\
\hline & & & & 0.1493 & 56.0 & 1.989 & 1.4914 \\
\hline \multirow[t]{2}{*}{ "Poor" } & \multirow[t]{2}{*}{32} & 20 & 0.1175 & 0.1475 & 189.4 & 3.495 & 1.3324 \\
\hline & & & & 0.1501 & 189.0 & 4.014 & 1.4962 \\
\hline
\end{tabular}


was simply accomplished by subtracting off the midpoint of the $X_{i}$ range and dividing by half of the $X_{i}$ range.

The essence of a multiple linear regression analysis is to estimate the model coefficients (the effects) and judge them as either statistically significant or as not statistically significant. Those model terms with coefficients that are judged as not statistically significantly different from zero are dropped from the model. Table 5 contains the results from the multiple linear regression analysis. It shows the statistically significant model terms, the estimated coefficients (the effects) and their confidence level. Note that the estimated coefficients in the table are appropriate for use with the scaled $X_{i}$ 's. The interpretation of a model term's confidence level is that its coefficient is distinguishable from zero with that degree of certainty or probability. Model terms with confidence levels less than 90 percent were dropped from the model. The statistical model equation for the maximum RMS outlet pressure oscillation is shown in equation (4). It is valid over the ranges of the control variables studied. the number of data points (30 in this case) and $P$ is the number of estimated model coefficients ( 11 in this case). It is a measure of goodness of fit of the model to the data. $S_{Y . X}$ for the response $\mathrm{Y}=$ maximum RMS outlet pressure was 33.99. Approximate 95 percent confidence intervals on future model predictions (sometimes referred to as 95 percent prediction errors) are $\pm 2 S_{Y . X}$ or in this case \pm 68 . To put this in perspective, note that the total range of the response $\mathrm{Y}=$ maximum $\mathrm{RMS}$ outlet pressure was from 1.2 to 338.3 . Therefore, the resultant regression model was not a very precise predictor of the response. This was, however, the anticipated result based on the analysis of the "repeats." Hence, while the model is not an extremely precise predictor of the response $\mathrm{Y}=$ maximum RMS outlet pressure, it does reveal many statistically significant effects and trends.

Perhaps the most interesting conclusion from the fitted model is that there is no direct linear affect of heat flux on the occurrence of the instabilities. In addition, heat

$$
\begin{aligned}
R M S & \left(P_{\text {out }}\right)_{1.0}=44.82+31.98\left(\frac{L-17.0}{3.0}\right)+37.50\left(\frac{D_{i}-0.14875}{0.03125}\right)+17.30\left(\frac{\dot{m}-0.1118}{0.0401}\right)-31.22\left(\frac{T_{i}-121.6}{78.9}\right) \\
& +27.15\left(\frac{L-17.0}{3.0}\right)\left(\frac{D_{i}-0.14875}{0.03125}\right)-29.65\left(\frac{L-17.0}{3.0}\right)\left(\frac{T_{i}-121.6}{78.9}\right)+18.20\left(\frac{D_{i}-0.14875}{0.03125}\right)\left(\frac{\dot{m}-0.1118}{0.0401}\right) \\
& -24.00\left(\frac{D_{i}-0.14875}{0.03125}\right)\left(\frac{T_{i}-121.6}{78.9}\right)+24.80\left(\frac{\dot{m}-0.1118}{0.0401}\right)\left(\frac{Q-3.005}{1.016}\right)-21.11\left(\frac{T_{i}-121.6}{78.9}\right)\left(\frac{Q-3.005}{1.016}\right)
\end{aligned}
$$

Two important summary statistics for a multiple regression analysis are $R^{2}$ and $S_{Y . X} \cdot R^{2}$ is the fraction of the total variability in the $Y$ response that is being explained by the model. It is calculated by $R^{2}=\left[\Sigma\left(Y_{\text {Predicted }}-\right.\right.$ $\left.\left.\mathrm{Y}_{\mathrm{Bar}}\right)\right] /\left[\Sigma\left(\mathrm{Y}_{\text {Actual }}-\mathrm{Y}_{\mathrm{Bar}}\right)\right]$, where $\mathrm{Y}_{\mathrm{Bar}}=$ the mean of all of the response data. The $R^{2}$ for the response $Y=$ maximum RMS outlet pressure was 0.8478 . Hence, about 85 percent of the variability in the response was accounted for by the final regression model. The standard deviation of regression is $S_{Y . X}=\left[\Sigma\left(Y_{\text {Actual }}-Y_{\text {Predicted }}\right)^{2 /(N-P)}\right]^{1 / 2}$, where $N$ is

\begin{tabular}{|c|c|c|}
\hline Model Term & $\begin{array}{l}\text { Estimated } \\
\text { coefficient }\end{array}$ & $\begin{array}{c}\text { Confidence } \\
\text { level. } \\
\text { percent } \\
\end{array}$ \\
\hline Intercept & 44.82 & 99.99 \\
\hline Length linear term & 31.98 & 99.98 \\
\hline Diameter linear term & 37.50 & 99.99 \\
\hline Mass flow rate linear term & 17.30 & 96.91 \\
\hline Inlet temperature linear term & -31.22 & 99.89 \\
\hline Length* diameter interaction & 27.15 & 99.90 \\
\hline Length $*$ inlet temp interaction & -29.65 & 99.85 \\
\hline Diameter*mass flow rate interaction & 18.20 & 98.11 \\
\hline Diameter*inlet temp interaction & -24.00 & 99.22 \\
\hline Mass flow rate* heat flux interaction & 24.80 & 99.27 \\
\hline Inlet temp*heat flux interaction & -21.11 & 96.59 \\
\hline
\end{tabular}

TABLE 5.-MULTIPLE LINEAR REGRESSION RESULTS FOR $Y$ = MAXIMUM RMS OUTLET PRESSURE. flux appears in only two (of a possible four) interaction terms, with mass flow rate and inlet temperature.

There are four linear terms in the fitted model, indicating the linear effects of length, diameter, mass flow rate, and inlet temperature. When significant interactive effects are present, it is best not to try to understand the linear effects by looking at estimated coefficients in a table. However, it is interesting to note that all of the coefficients for inlet temperature are negative (i.e., the linear term, and the interactions with length, diameter, and heat flux). This would seem to imply that the instabilities should weaken with increasing inlet temperature. As inlet temperature increases, buoyancy forces become less significant due to decreasing viscosity, which causes Grashof number to decrease while Reynolds number increases. The negative coefficients on the inlet temperature terms could therefore imply that buoyancy forces are a significant contributor to the instabilities. However, buoyancy forces are also affected by other variables that have the opposite effect on the instabilities. For example, increasing mass flow rate increases Reynolds number and subsequently decreases the significance of the buoyancy forces. All coefficients on the mass flow rate terms, however, are positive, which would seem to indicate that 
increasing mass flow rate increases the strength of the instabilities, even though buoyancy forces are decreased. A more complete evaluation of the effects of buoyancy forces is discussed later in this section.

The best way to view the linear and interactive effects within the model is with three-dimensional plots. Figures 6 to 11 depict not only the four significant linear effects of the factors studied, but also show the six statistically significant interactions. It is important to note the direction of low to high values on the $x$-axes, as it was varied on each plot to provide the best three dimensional view.

The first interaction term in the model is the interaction between length and diameter. Figure 6 shows the effect of length and diameter on maximum predicted pressure oscillation when all other variables are held constant at a mid-point value. If there was no interaction between the two variables, then the linear effect of diameter would not depend on the value of length. However, figure 6 clearly shows that there is an interaction. At short length, the maximum RMS pressure oscillation increases only slightly with increasing diameter. However, at long length, the RMS pressure oscillation increases significantly with increasing diameter. Similarly, at small diameter, the RMS pressure oscillation increases slightly with increasing length, but at large diameter the RMS pressure oscillation increases significantly with increasing length.
The second interaction term in the model is the interaction between length and inlet temperature. Figure 7 shows the effect of varying these two parameters while all others are held constant at a midpoint value. From the figure it can be seen that at short length, the RMS pressure oscillation is unaffected by inlet temperature. At long lengths, however, the decrease in pressure oscillation with increasing inlet temperature is significant. When looking at the trends of the graph for constant inlet temperature, the trends are similar, but reversed. At high inlet temperature, the RMS pressure oscillation is unaffected by length. At low inlet temperature, however, the increase in pressure oscillation with increasing length is significant.

The third interaction term in the model is the interaction between diameter and mass flow rate. Figure 8 shows this interaction. At low values of diameter, the RMS pressure oscillations are relatively unaffected by increasing mass flow rate. At high diameter, the pressure oscillations increase with increasing mass flow rate. At both low and high values of mass flow rate, the pressure oscillations increase significantly with increasing diameter, with the increase at high mass flow rate being more pronounced than at low mass flow rate.

The fourth interaction term in the model is the interaction between diameter and inlet temperature. Figure 9 shows the relationship between the two variables.

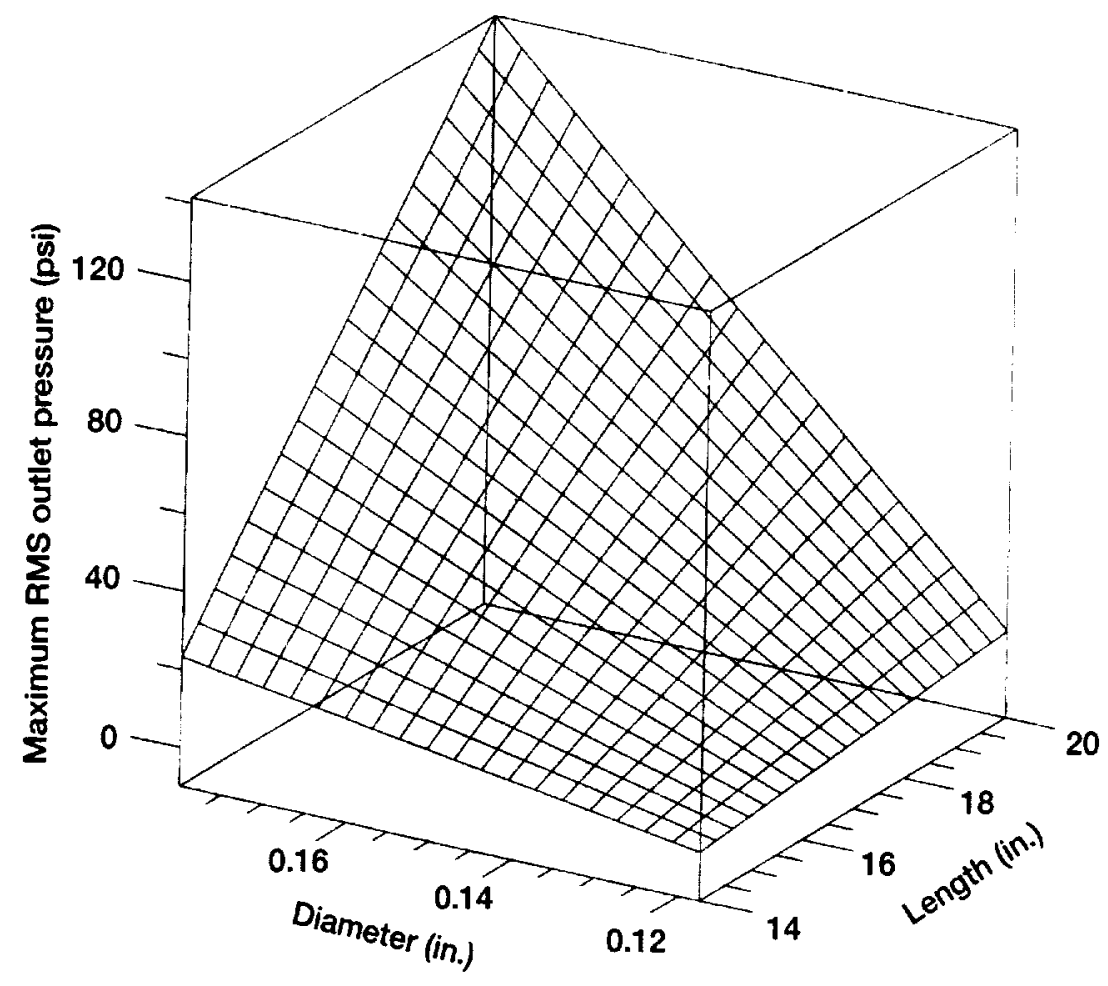

Figure 6. - Interaction between diameter and length (mass flow rate, inlet temperature, and heat flux held constant at mid-point). 


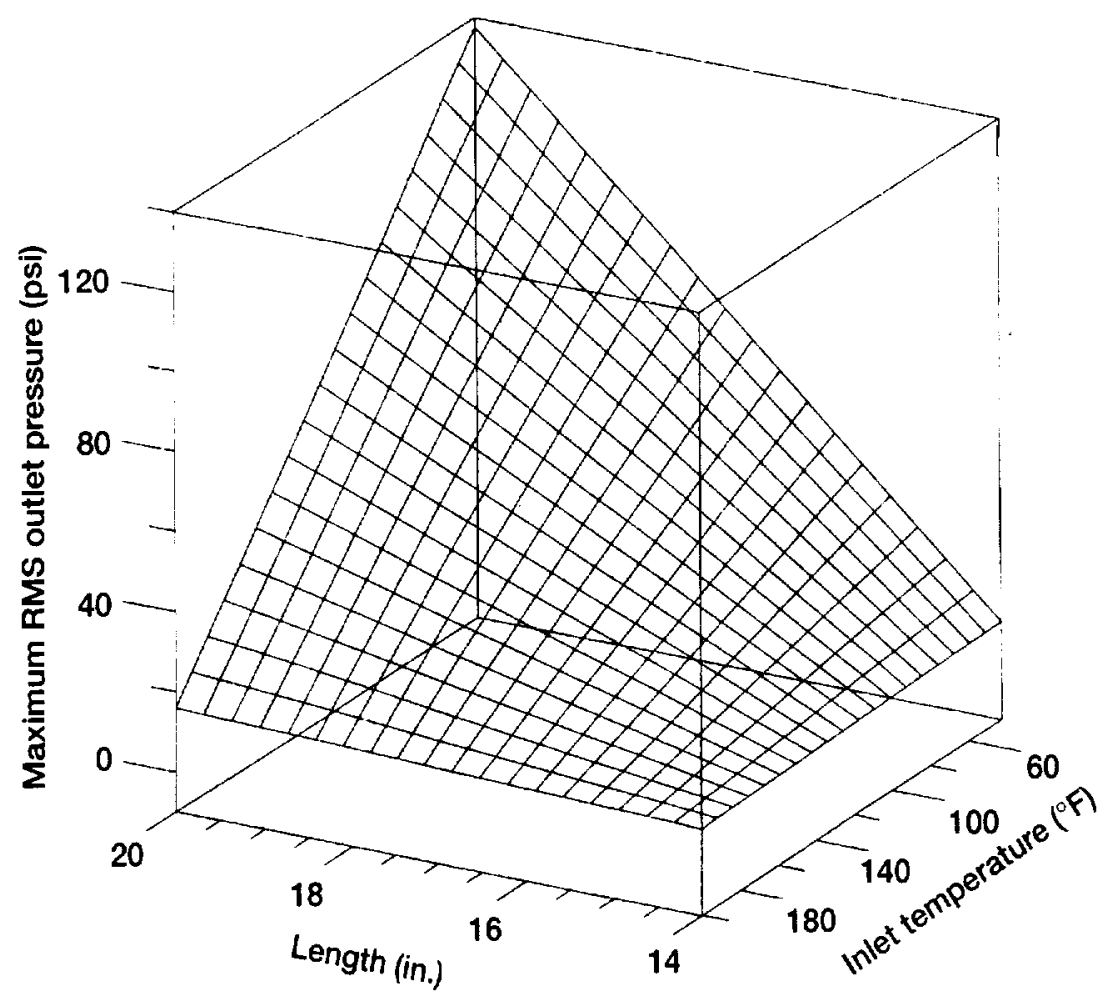

Figure 7.- Interaction between length and inlet temperature (diameter, mass flow rate, and heat flux held constant at mid-point).

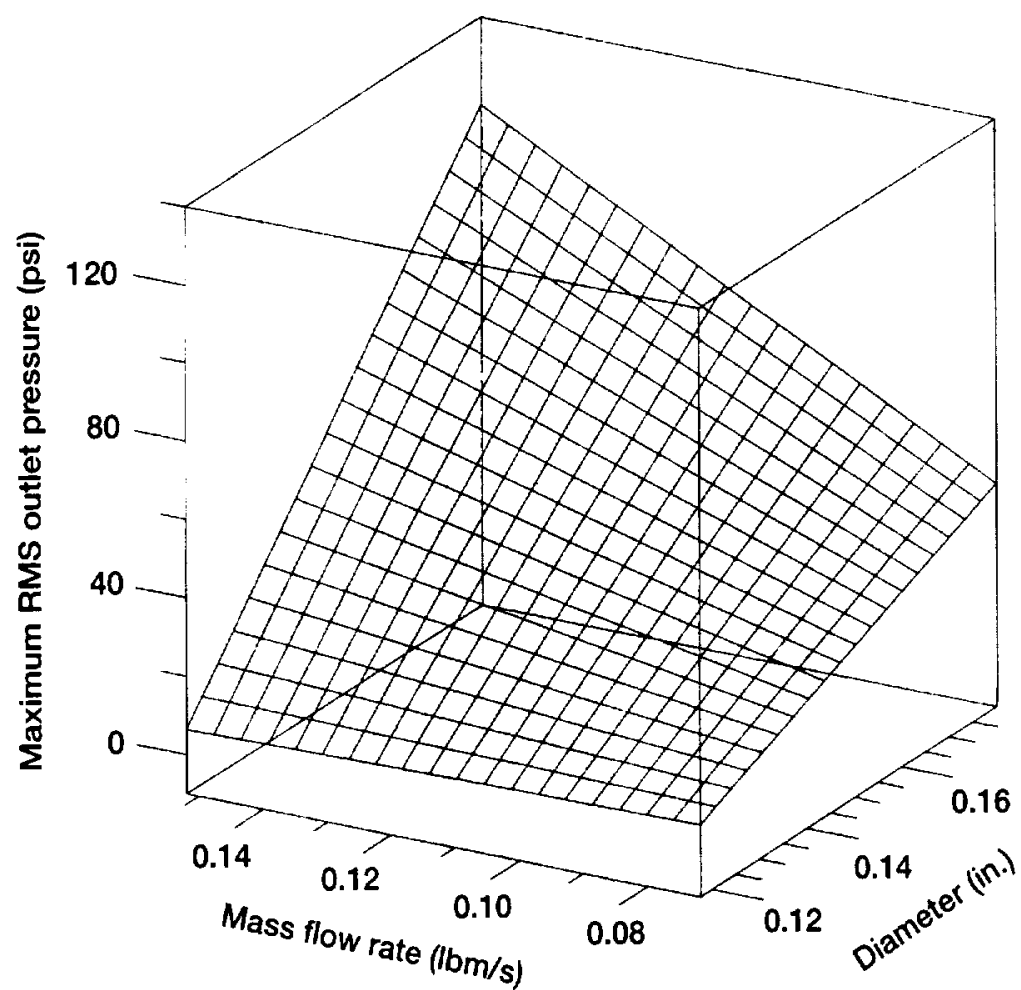

Figure 8.- Interaction between mass flow rate and diameter (length, inlet temperature, and heat flux held constant at mid-point). 


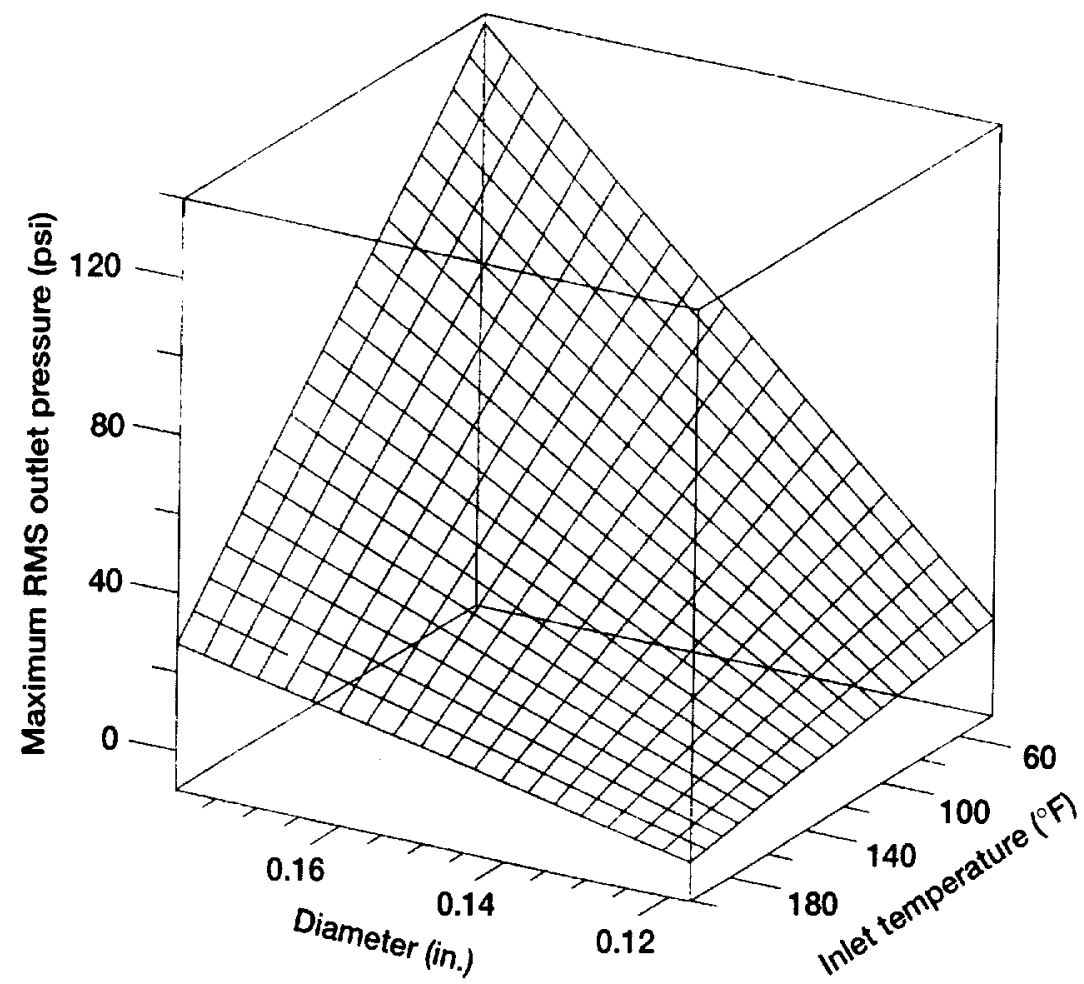

Figure 9.-Interaction between diameter and inlet temperature (length, mass flow rate, and heat flux held constant at mid-point).

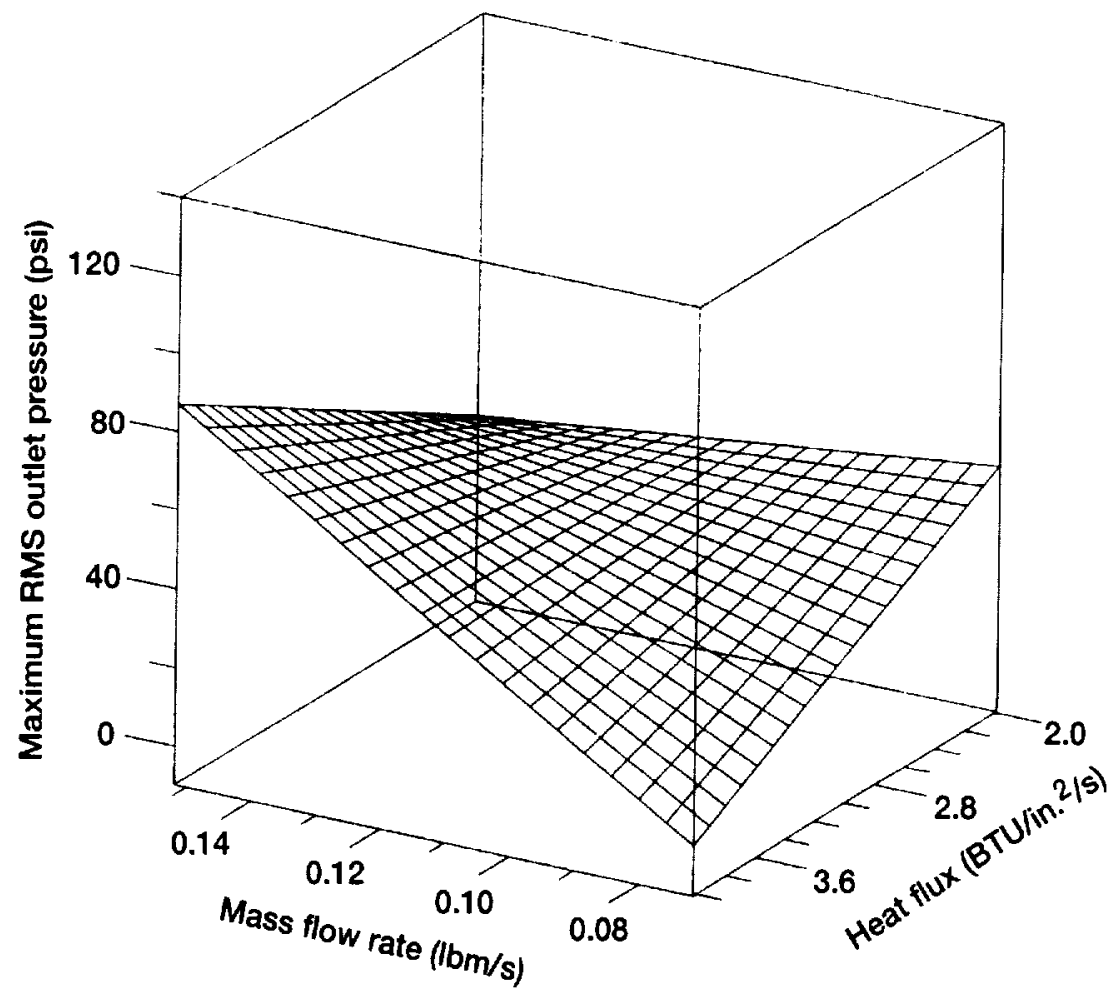

Figure 10.- Interaction between mass flow rate and heat flux (length, diameter, and inlet temperature held constant at mid-point). 


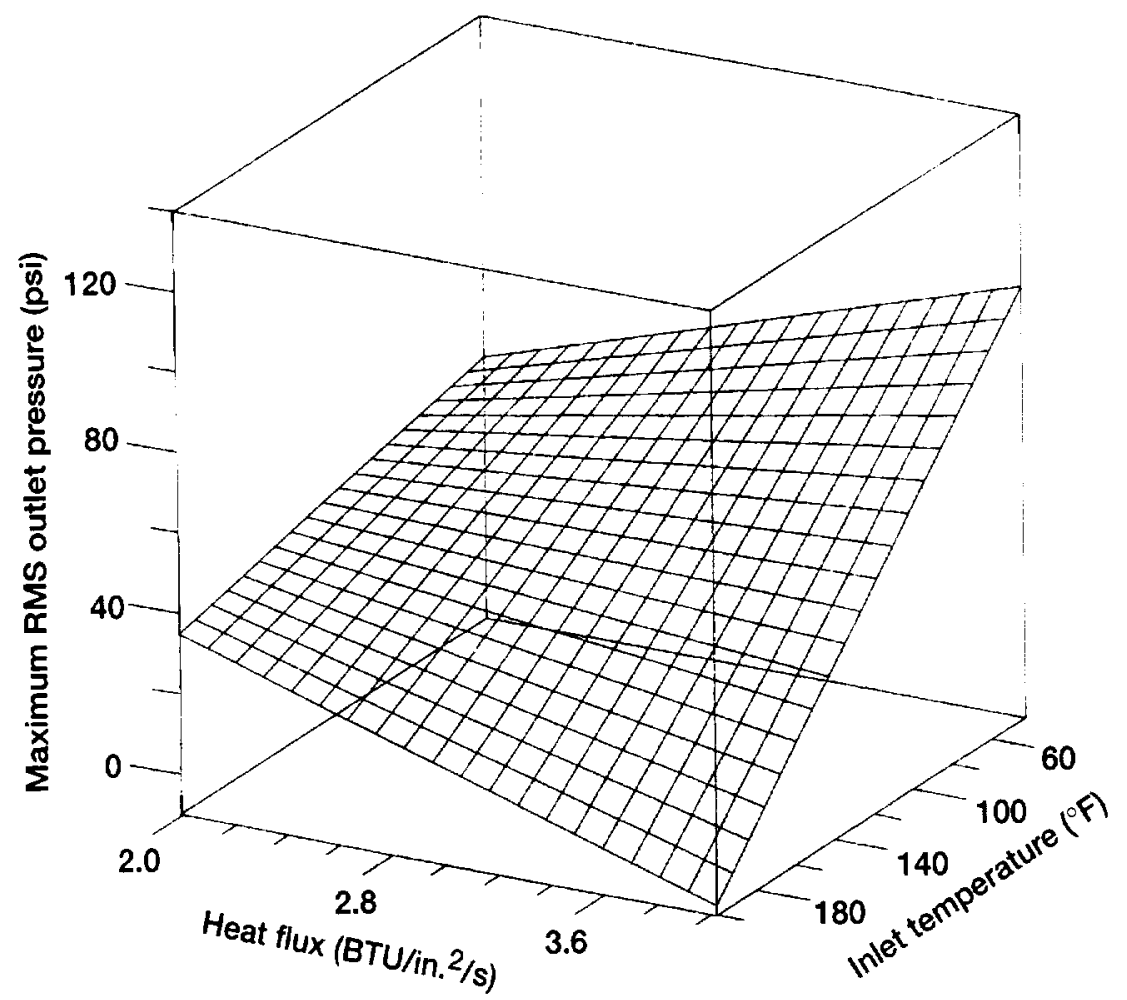

Figure 11.-Interaction between heat flux and inlet temperature (length, diameter, and mass flow rate held constant at mid-point).

At both low and high diameter, the RMS pressure oscillation decreases with increasing inlet temperature. The rate of decrease is much steeper at high diameter. At both low and high values of inlet temperature, the pressure oscillations increase with increasing diameter, although the rate of increase is much more significant at low inlet temperature.

The fifth interaction term in the model is the interaction between mass flow rate and heat flux. Figure 10 shows this interaction. At high mass flow rate there is only a small increase in pressure oscillations with increasing heat flux. However, at low mass flow rate there is a significant decrease in pressure oscillations with increasing heat flux. At low heat flux, there is little effect on pressure oscillations with increasing mass flow rate. However, at high heat flux there is a significant increase in pressure oscillations with increasing mass flow rate.

The last interaction term in the model is the interaction between heat flux and inlet temperature. This is illustrated in figure 11. At both low and high heat flux, the pressure oscillations decrease with increasing inlet temperature, with a steeper decrease at high heat flux. At low inlet temperature, there is an increase in pressure oscillations with increasing heat flux, while at high inlet temperature there is a decrease in pressure oscillations with increasing inlet temperature.

\section{Prediction of Instabilities}

To evaluate the ability of the model to predict whether a set of conditions will provide stable or unstable flow, equation (4) was used to calculate predicted values of RMS pressure for each of the set of test conditions. These results are listed in table 6 and shown in figure 12 plotted against the actual RMS pressure results. To delineate between a stable and unstable response, it was (arbitrarily) determined that a maximum RMS pressure of 10 psi or greater indicated that the condition was unstable. In the figure, a vertical line passing through $10 \mathrm{psi}$ on the $\mathrm{x}$-axis shows the experimental split between stable and unstable cases. Every response that falls to the right of this line is considered unstable. A horizontal line passing through 10 psi on the $y$-axis shows the predicted split between stable and unstable cases. Every response that falls above this line is predicted to be unstable.

If the model provided perfect predictions of whether a condition would produce a stable or unstable response, then every point to the right of the experimental dividing line would also fall above the model's dividing line. Similarly, every point to the left of the experimental dividing line would fall below the model's dividing line. In figure 12, a majority of the points follow this pattern ( 8 unstable points and 10 stable points). To understand 
TABLE 6.-ACTUAL VERSUS MODEL PREDICTED RESPONSE VALUES.

\begin{tabular}{|c|c|c|c|c|c|c|c|}
\hline \multirow[t]{2}{*}{$\begin{array}{c}\text { Test matrix } \\
\text { number }\end{array}$} & \multicolumn{5}{|c|}{ Control Variables } & \multicolumn{2}{|c|}{$\begin{array}{c}\text { Maximum RMS } \\
\text { Outlet Pressure (psi) }\end{array}$} \\
\hline & $\begin{array}{l}\text { Length. } \\
\text { in. }\end{array}$ & $\begin{array}{c}\text { Diameter, } \\
\text { in. }\end{array}$ & $\begin{array}{c}\text { Mass flow rate, } \\
\text { lbnds }\end{array}$ & $\begin{array}{c}\text { Inlet } \\
\text { temperature, } \\
{ }^{\circ} \mathrm{F}\end{array}$ & $\begin{array}{l}\text { Heat flux. } \\
\text { BTU/in. }{ }^{2} / \mathrm{s} \text { ) }\end{array}$ & Actual & Predicted \\
\hline 2 & 14 & 0.18 & 0.0717 & 58 & 2.66 & 31.1 & 11.0 \\
\hline 2 & 14 & 0.18 & 0.0767 & 66 & 3.57 & 1.25 & 6.24 \\
\hline 2 & 14 & 0.18 & 0.0751 & 66 & 3.75 & 1.22 & 2.96 \\
\hline 2 & 14 & 0.18 & 0.0750 & 68 & 4.00 & 27.9 & -0.34 \\
\hline 3 & 14 & 0.18 & 0.0748 & 201 & 2.04 & 1.60 & 6.70 \\
\hline 3 & 14 & 0.18 & 0.0748 & 186 & 1.99 & 1.41 & 9.50 \\
\hline 5 & 14 & 0.18 & 0.1464 & 57 & 2.04 & 65.7 & 38.0 \\
\hline 5 & 14 & 0.18 & 0.1484 & 55 & 2.02 & 2.11 & 37.9 \\
\hline 5 & 14 & 0.18 & 0.1498 & 62 & 2.00 & 1.36 & 37.08 \\
\hline 8 & 14 & 0.18 & 0.1481 & 184 & 4.01 & 109 & 40.7 \\
\hline 8 & 14 & 0.18 & 0.1435 & 196 & 4.00 & 1.68 & 26.6 \\
\hline 8 & 14 & 0.18 & 0.1458 & 194 & 4.00 & 3.11 & 31.4 \\
\hline 9 & 14 & 0.1175 & 0.0768 & 44 & 2.00 & 1.26 & -18.2 \\
\hline 12 & 14 & 0.1175 & 0.0756 & 183 & 3.99 & 1.55 & -17.0 \\
\hline 14 & 14 & 0.1175 & 0.1500 & 43 & 3.99 & 1.40 & 22.8 \\
\hline 15 & 14 & 0.1175 & 0.1434 & 186 & 2.02 & 1.39 & 18.1 \\
\hline 17 & 20 & 0.18 & 0.0748 & 51 & 2.02 & 152 & 188 \\
\hline 20 & 20 & 0.18 & 0.0776 & 189 & 2.40 & 96.0 & 61.6 \\
\hline 20 & 20 & 0.18 & 0.0788 & 200 & 2.90 & 7.19 & 32.1 \\
\hline 22 & 20 & 0.18 & 0.1519 & 43 & 4.02 & 338 & 307 \\
\hline 23 & 20 & 0.18 & 0.1488 & 180 & 2.02 & 99.7 & 104 \\
\hline 25 & 20 & 0.1175 & 0.0742 & 76 & 2.00 & 31.8 & 45.3 \\
\hline 26 & 20 & 0.1175 & 0.0753 & 0 & 4.01 & 80.6 & 28.3 \\
\hline 26 & 20 & 0.1175 & 0.0752 & 62 & 3.99 & 1.36 & 37.1 \\
\hline 27 & 20 & 0.1175 & 0.0775 & 183 & 2.00 & 1.26 & 21.4 \\
\hline 27 & 20 & 0.1175 & 0.0757 & 175 & 2.00 & 1.30 & 24.2 \\
\hline 29 & 20 & 0.1175 & 0.1482 & 70 & 2.02 & 1.33 & 0.25 \\
\hline 29 & 20 & 0.1175 & 0.1493 & 56 & 1.99 & 1.49 & 1.22 \\
\hline 32 & 20 & 0.1175 & 0.1501 & 189 & 4.01 & 1.50 & -14.6 \\
\hline 32 & 20 & 0.1175 & 0.1475 & 189 & 3.50 & 1.33 & -18.5 \\
\hline
\end{tabular}

why the model fails to accurately predict the nature of the remaining test conditions, the remaining points will be considered in two groups.

There are two points, which are circled and labeled in the figure, that were experimentally unstable, but were predicted to be stable by the model. These two points were both from test matrix 2. It can be seen from Table 3 that although these two points were unstable, the other two tests, or "repeats," at this condition were stable. Therefore, it is understandable that the model would predict this condition to be on the borderline between stable and unstable.

There are ten points that were experimentally stable, but were predicted to be unstable by the model. These are also circled and labeled in the figure. Of these ten points, six of them came from a test matrix condition (test matrix $5,8,20$, and 26 ) where a repeat test produced an unstable response. Two of the ten points were from a condition (test matrix 14 and 15) where there is no repeat data available. These results can be summarized by observing that any condition that produced at least one strongly unstable response ( $>30$ psi RMS) will be predicted unstable by the model, even if some repeats were experimentally stable.
The only inconsistency from the results of the fitted model is that it predicts the condition at test matrix 27 to be unstable, even though both of the experimental tests produced a stable response. The answer may lie in the fact that at least one curvilinear effect is present which was not estimable with the DOE strategy chosen.

\section{Enhanced Heat Transfer}

Previous experiments have noted that the onset of the instabilities coincides with the beginning of enhanced heat transfer. ${ }^{5.9}$ However, other experiments have concluded that the enhancement in heat transfer during unstable flow is minimal. ${ }^{12}$ Figure 13 shows heat flux as a function of coolant side wall temperature for two runs of test matrix 26 . Although these two tests were run at the same conditions, one remained stable (reading 78), while the other became unstable (reading 29). The data from the stable test shows a steady, slightly steeper than linear, increase in heat flux with wall temperature. This is typical of forced convection cooling. The data from the unstable test shows poorer initial cooling, as evidenced by the lower slope. However, shortly after pressure 


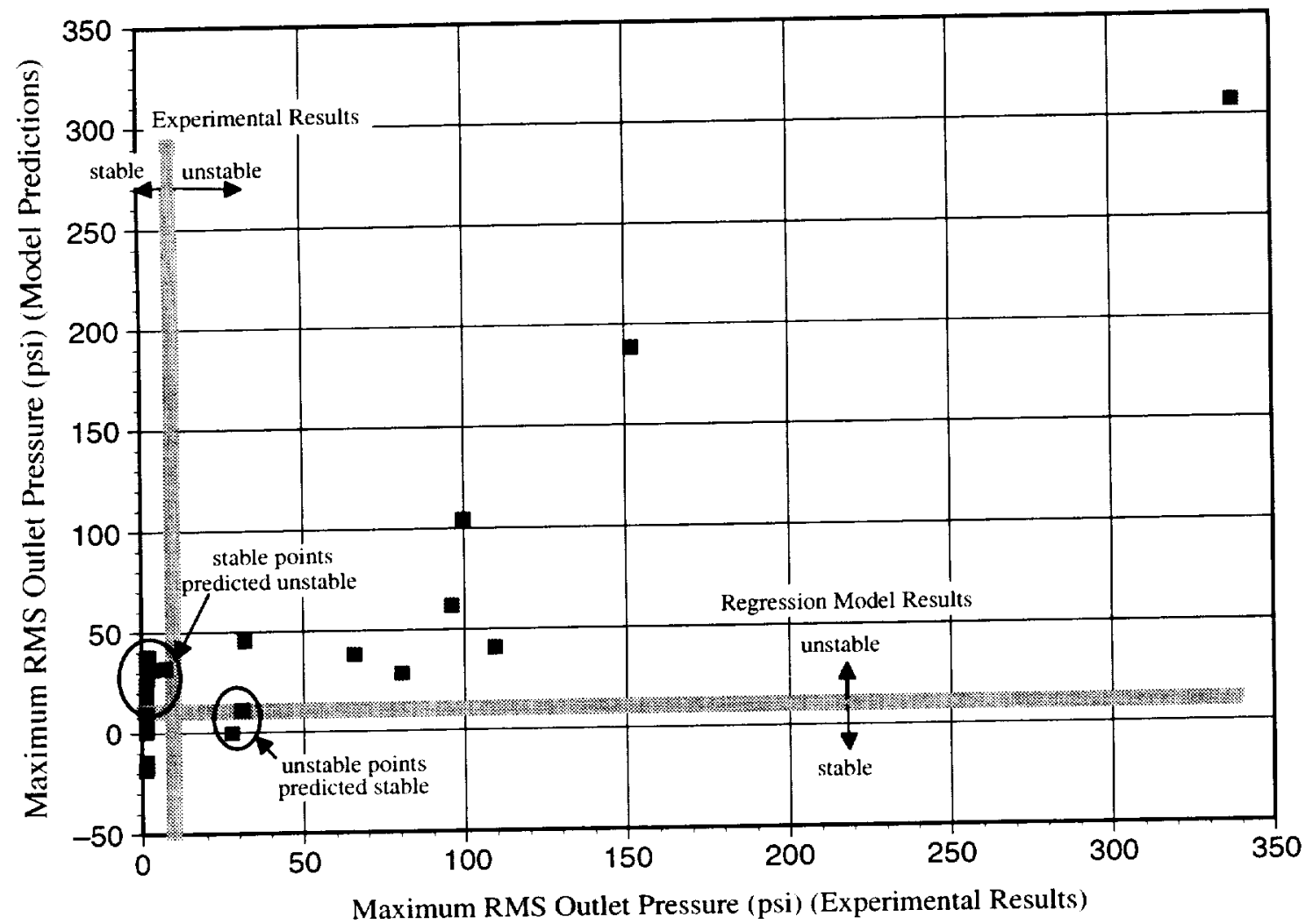

Figure 12.-Evaluation of regression model for maximum RMS outlet pressure.

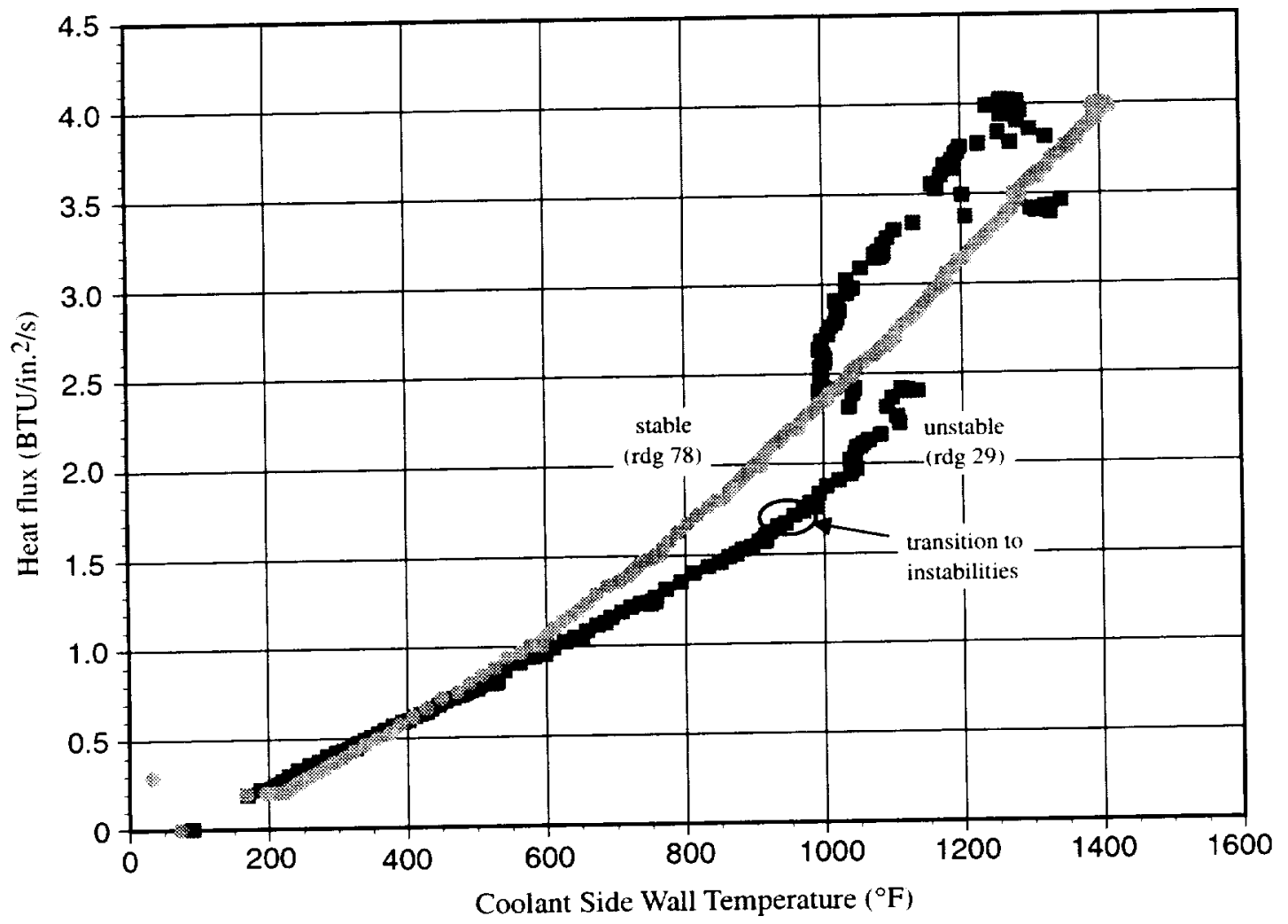

Figure 13.-Comparison of coolant wall temperatures for text matrix 26. 
oscillations began, an enhanced cooling mechanism allowed a large increase in heat flux with very little increase in wall temperature. Because of this enhanced cooling, the wall temperature of the unstable test at a heat flux of 4 BTU/in. ${ }^{2} / \mathrm{s}$ was slightly lower than the wall temperature of the stable test. However, this enhanced cooling provided only a 10 percent improvement in wall temperature rise, well below the 40 to 100 percent improvement noted in earlier works. ${ }^{5.9}$

One reason for the lower cooling enhancement reported here is that in this experimental program, certain sets of test conditions were repeated (such as test matrix 26), and these repeats were inconsistent in terms of providing stable or unstable flow. While this inconsistency in producing instabilities caused difficulties in developing a predictive model, it did provide an opportunity to better evaluate the enhanced cooling obtained during unstable operation. When the data from the unstable reading 29 is evaluated independently, then it appears that cooling was enhanced nearly 75 percent (based on the slopes of the heat flux curve before and after the instabilities). Comparing the final slope

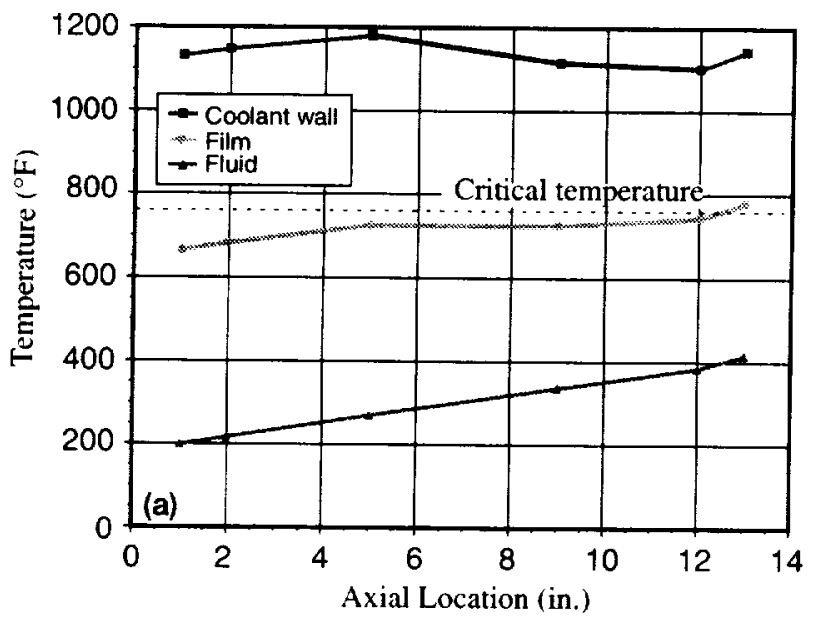

of the unstable reading 29 with the slope of the stable reading 78 , however, shows no difference in cooling. The 10 percent improvement in wall temperature at the final conditions is merely achieved from the discontinuity that occurred shortly after the instabilities began. This conclusion more closely matches the results reported in reference 12 , where the experimental data showed minimal improvement in heat transfer during the instabilities.

\section{Temperature Dependence}

As discussed earlier, the high and low values of the control variables were selected such that they would produce wall, film, and bulk fluid temperature profiles that were below, near, or above critical temperature of the fuel. It had been reported in previous experiments ${ }^{9.10}$ that approaching critical temperature, where there are some sharp changes in fluid properties, was the predominant cause of the instabilities. Figure 14 shows the coolant wall, fluid, and film temperature profiles along the entire heated length for several tests. In figure 14(a), the temperature profiles are shown for test matrix $8(\operatorname{rdg} 36)$

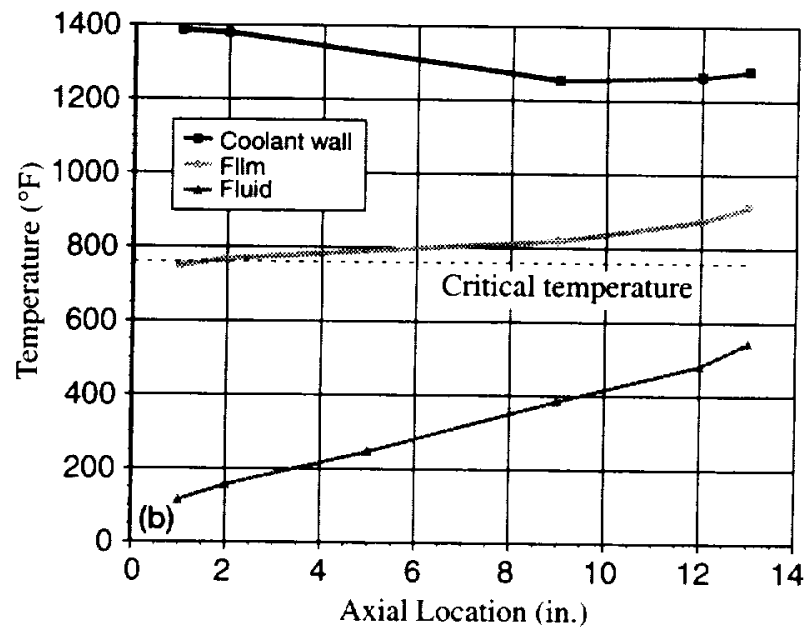

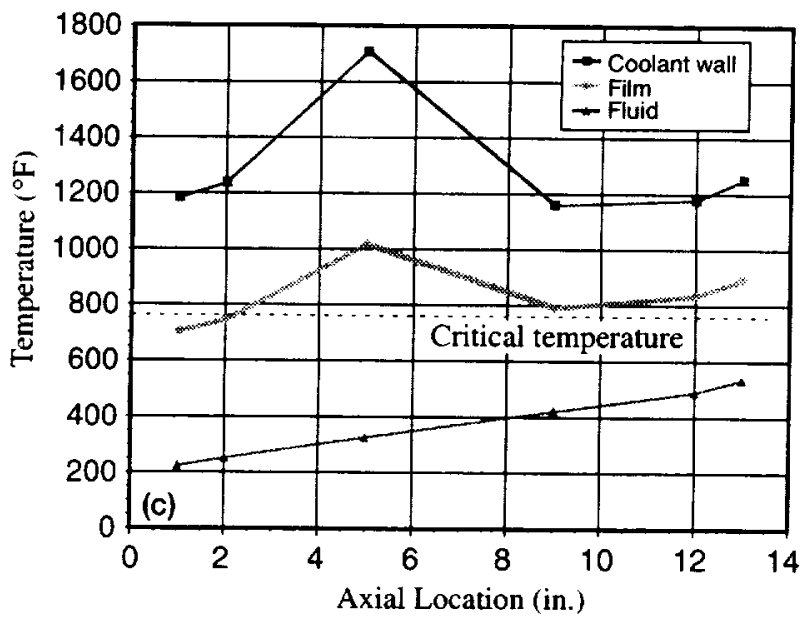

Figure 14.-Temperature profiles. (a) Start of instabilities, test matrix $8, \operatorname{Rdg} 36$. (b) Start of instabilities, test matrix 2, Rdg 81. (c) Target conditions (stable), test matrix 8, Rdg 80 . 
at the conditions where instabilities first started (heat flux approximately equal to $2.66 \mathrm{BTU} / \mathrm{in} .{ }^{2} / \mathrm{s}$ ). It can be seen in the figure that the film temperature rose above critical temperature near the end of the test section. One could therefore conclude that sharp changes in the fluid properties near the wall at this location created a boiling-like phenomenon which triggered fluid instabilities that were propagated throughout the test section.

In figure 14(b), the temperature profiles are shown for test matrix $2(\operatorname{rdg} 81)$, also at the conditions where instabilities first started (heat flux approximately equal to 3.0 BTU/in. ${ }^{2} / \mathrm{s}$ ). In this case, the film temperature rose above the critical temperature near the beginning of the test section. The conclusion based on this figure would therefore be that sharp changes in fluid properties near the wall are required over a significant portion of the test section before the boiling-like phenomenon triggers fluid instabilities. In figure $14(\mathrm{c})$, the temperature profiles are shown for test matrix $8(\operatorname{rdg} 80)$ at the target conditions. Although the film temperature rose above the critical temperature near the beginning of the test section as in figure 14(b), there were no instabilities in this test. The conclusion based on this figure would therefore be that film temperatures at or above critical temperature do not trigger the instabilities. This contradicts the apparent correlation seen in figures 14(a) and (b).

This apparent lack of correlation with critical temperature can be viewed in another manner in figure 15 .
In this figure, maximum RMS pressure is plotted as a function of the maximum wall, film, and fluid temperatures. A logarithmic curve fit line is shown for each set of data. Although the curve fit lines indicate an overall trend that increasing temperature results in some increase in RMS pressure (i.e., increasing instability), the scatter about the lines would prevent drawing any strong conclusion.

\section{Velocity Dependence}

There are certain combinations of the control variables that produce other physical quantities that could be considered relevant to the fluid flow behavior. Inlet velocity is a function of three control variables (mass flow rate, diameter, and inlet temperature) through the relationship:

$$
V=\frac{\dot{m}}{\rho_{b} A}=\frac{4 \dot{m}}{\pi \rho_{b} D_{i}^{2}}
$$

where $\rho_{b}$ is the bulk density of the fluid and is a function of inlet temperature. Because mass flow rate and diameter are constant throughout the test section, and fluid temperature continually increases, velocity will continually increase from the inlet to the outlet of the test section. Inlet velocity was therefore evaluated as the minimum velocity in the test section. A combination of high mass flow rate and low diameter produced a high inlet velocity. Similarly. a combination of low mass flow rate and high diameter

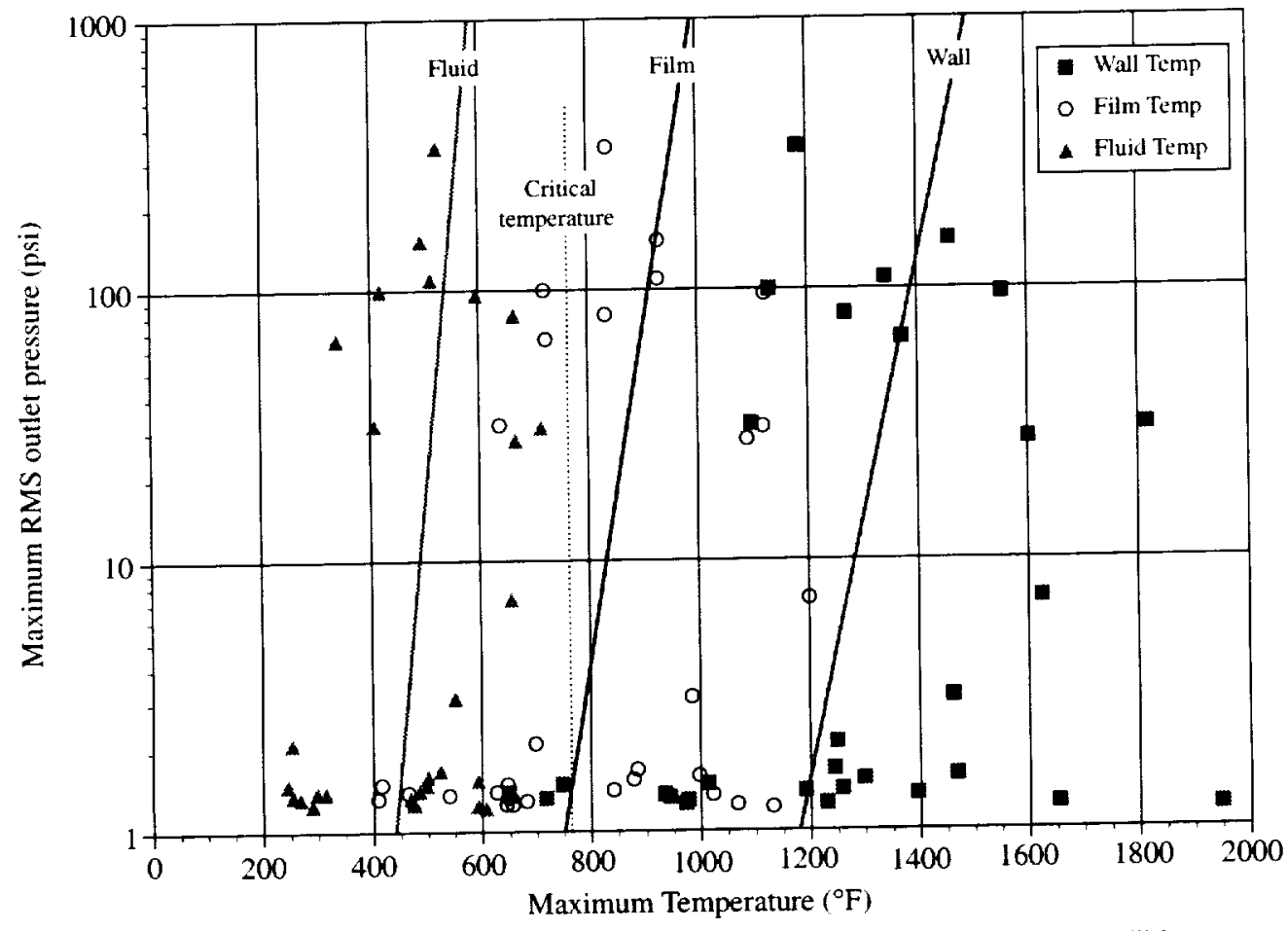

Figure 15.-Evaluation of relationship between temperatures and instabilities. 
produced a low inlet velocity. The high and low values of mass flow rate and diameter were carefully selected such that the combination of high mass flow rate and high diameter, and the combination of low mass flow rate and low diameter, produced a similar mid-level of velocity.

Figure 16 shows maximum RMS pressure as a function of inlet velocity. The three different velocity ranges are clearly seen in the figure. Low velocity is between 8 and $10 \mathrm{ft} / \mathrm{sec}$, mid velocity is between 17 and $23 \mathrm{ft} / \mathrm{sec}$, and high velocity is between 41 and $45 \mathrm{ft} / \mathrm{sec}$. The wide range of RMS pressure observed at the low and mid velocities precludes creating any functional dependence between pressure oscillation and inlet velocity. However, it is very clear from figure 16 that at the high velocity, all of the tests were stable. This seems to imply that the high velocity flow may prevent any instabilities from forming, even if the wall and fluid temperatures are such that instabilities may occur at lower velocities.

Inlet Reynolds number was evaluated in a plot similar to figure 16. The values of inlet Reynolds number were more varied than velocity, and the plot showed even less correlation between Reynolds number and RMS pressure. Although there were a few points at the highest values of Reynolds number $(45000)$ that showed no instabilities, the overall scatter of the plot prevented drawing any strong conclusions.

\section{Temperature and Velocity Dependence}

In reference 11 , results from heated tube tests conducted with supercritical propane are described. In these tests, flow oscillations were also observed, and the authors proposed a correlation between velocity and the ratio of maximum wall temperature to bulk fluid outlet temperature (fig. 8 of ref. 11). Therefore, these parameters were also plotted for the data in these tests to determine if a similar correlation exists. Figure 17 shows the maximum wall-to-bulk temperature ratio as a function of inlet velocity. Unfortunately, there is no correlation between these two parameters and flow stability.

\section{Buoyancy Forces}

Because the test section was mounted vertically, the Grashof number was calculated and compared to the Reynolds number to determine if buoyancy forces were significant and a possible contributor to the instabilities. The Grashof number includes some terms that need to be evaluated at the film temperature. Therefore, the "inlet" Grashof number was computed at the location of the first thermocouple, 1 in. into the heated portion of the test section. Figure 18(a) shows the maximum RMS pressure as a function of the buoyancy term, which is calculated from equation (3). A ratio greater than $1 \times 10^{-5}$ is considered indicative of significant buoyancy forces. Although the

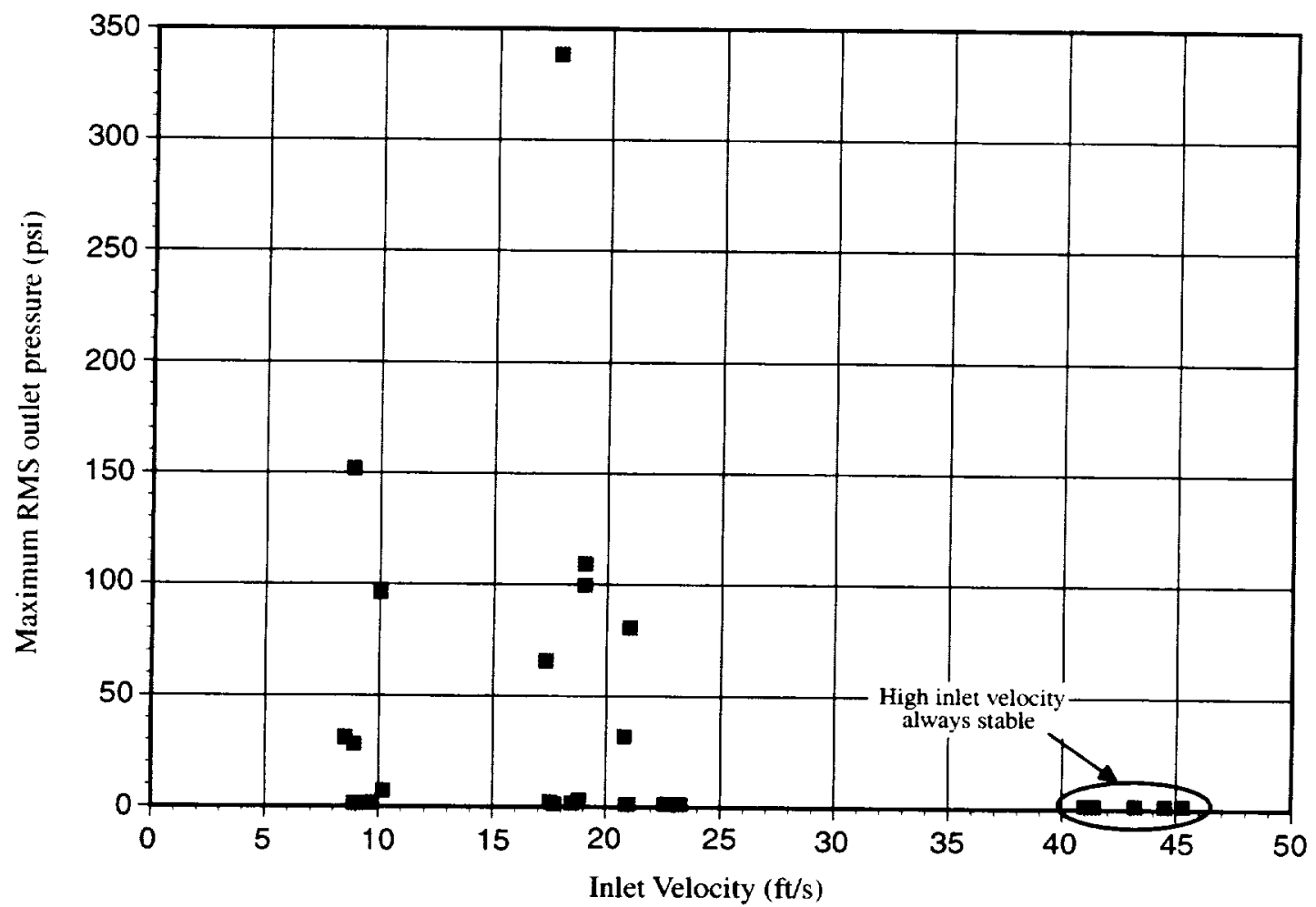

Figure 16.-Evaluation of effect of velocity on instabilities. 


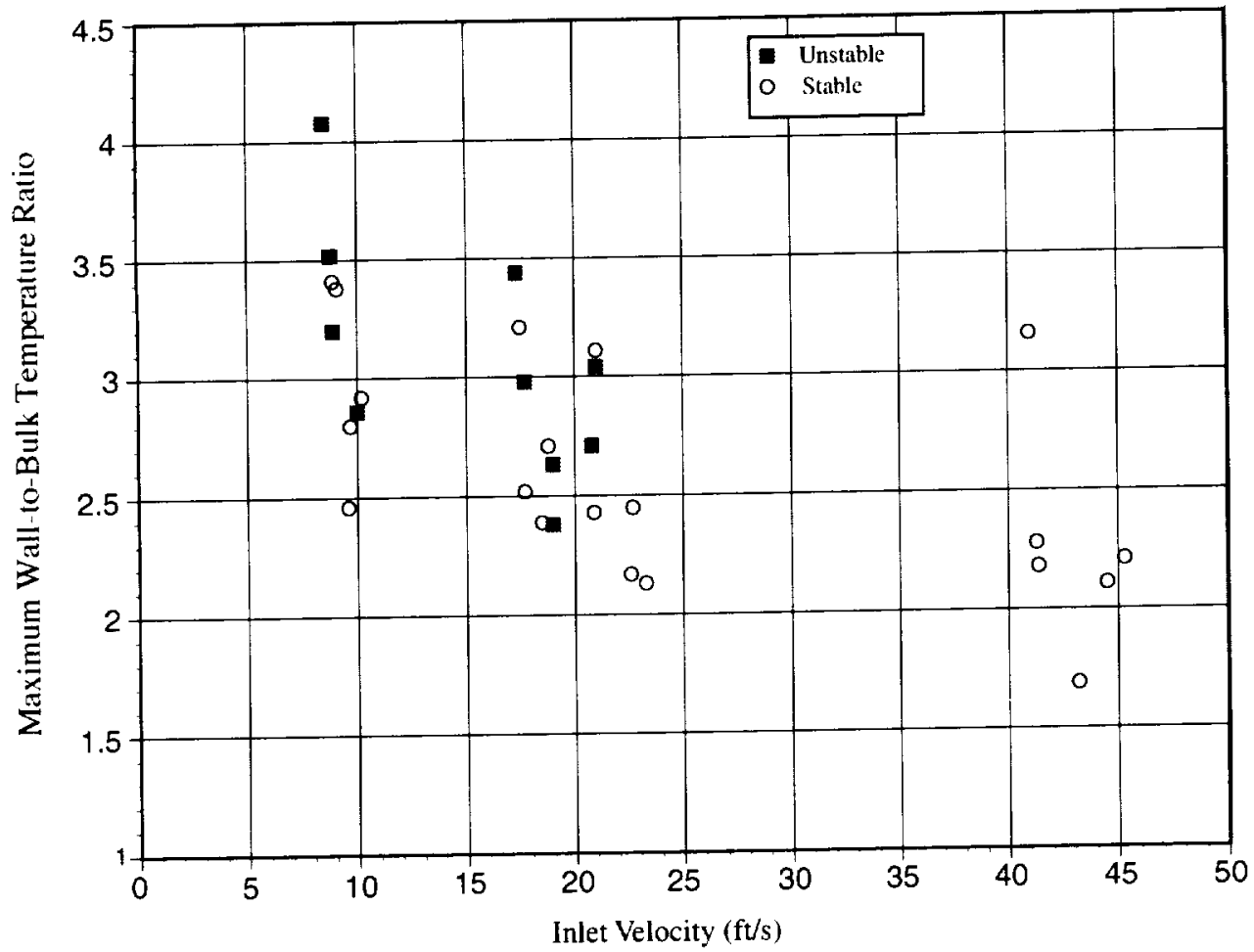

Figure 17.-Evaluation of relationship between wall-to-bulk temperature ratio and velocity.

figure shows that most of the unstable points did have significant buoyancy forces at the test section inlet. there are many stable test points that also had significant buoyancy forces. In addition, there is clearly no functional relationship between RMS pressure and the buoyancy term. Finally, figure 18(b) shows the maximum RMS pressure as a function of the buoyancy term approximately midway through the heated portion of the test section (at $9 \mathrm{in}$. in the $14 \mathrm{in}$. test section, and $10 \mathrm{in}$. in the $20 \mathrm{in}$. test sections). At this point in the test sections, the increasing temperatures have created conditions such that buoyancy forces are significant for only three of the tests; two of these were unstable. and one was stable.

\section{Conclusions}

A set of heated tube tests was conducted to determine the range of conditions that will cause fluid instabilities to occur during the heating of supercritical JP-7. The tests included in these experiments were defined by a rigorous DOE process. This DOE enabled the quantification of the linear and interactive effects of heated length, diameter. mass flow rate, fuel inlet temperature, and heat flux on the maximum RMS pressure oscillation. In addition, several physical variables were evaluated in an effort to find a functional relationship between these variables and the strength of the instabilities. From these tests, several conclusions can be made.

The occurrence of instabilities was inconsistent. At least one repeat test was conducted for nine of the seventeen test conditions. Of these nine test conditions, four of them were always stable. The other five produced both stable and unstable results. That is, there was no repeated test condition that always produced unstable results.

A statistical model that summarizes the trends and interactions caused by the control variables was created. Most significantly, the analysis determined that there is no simple linear affect of heat flux on the strength of the instabilities. However, the analysis did indicate that heat flux does have a significant effect on the instabilities interactive with both mass flow rate and inlet temperature. For all terms that include inlet temperature, the model coefficients are negative, indicating that increasing inlet temperature should cause the strength of the instabilities to decrease. All of the coefficients for terms that include the mass flow rate are positive, indicating that increasing mass flow rate should cause the strength of the instabilities to increase.

When using the statistical model to predict whether a condition will be stable or unstable, the model does a fair job. The majority of the test points that are predicted incorrectly are from the test conditions that had inconsistent repeats. That is, some of the stable tests that had an 

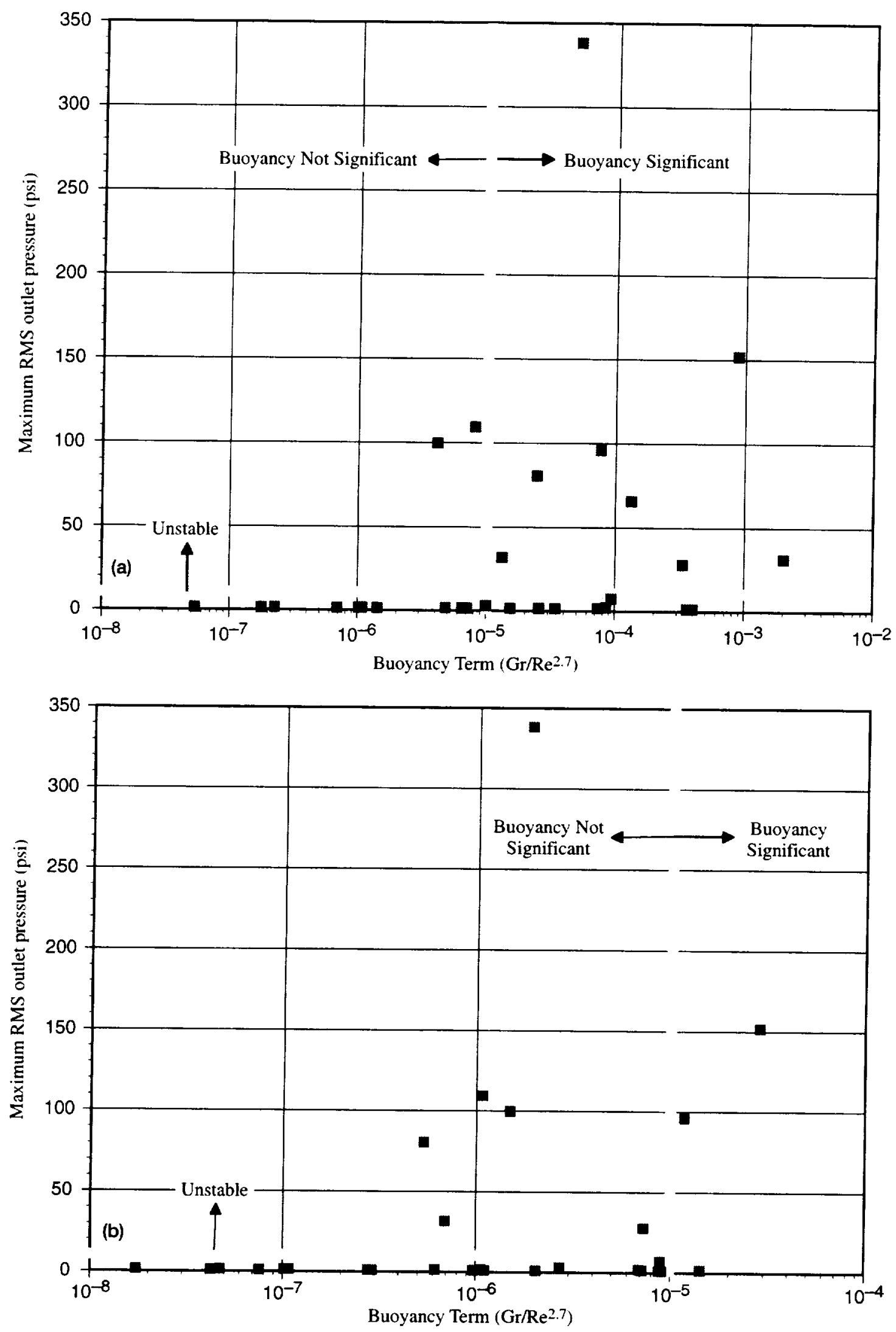

Figure 18.-Evaluation of effect of buoyancy forces on instabilities. (a) At TC1. (b) At approximately middle of test section (TC4). 
unstable repeat were predicted to be unstable, and some of the unstable tests that had a stable repeat were predicted to be on the borderline of stable.

There were no physical variables, or combination of variables, that could be found to completely explain the instabilities. The film temperature profile in the test section, and its proximity to critical temperature, did not seem to correlate to the onset of instabilities. Film temperature was at or above critical temperature for both stable and unstable tests. Tests run at the highest velocity were always stable, but mixed results at lower velocities preclude using velocity as the sole effect. Similarly, most of the unstable tests had significant buoyancy forces at the test section inlet. However, because many of the stable tests also had significant buoyancy forces, this can also not be used as the sole indicator of instabilities. Because typical flow parameters did not show any correlation, it is best to use the statistical model to predict what combination of diameter, length, mass flow rate, inlet temperature, and heat flux will trigger the flow instabilities in supercritical JP-7.

\section{$\underline{\text { References }}$}

1. Petley, D.H., and Jones, S.C., "Thermal Management for a Mach 5 Cruise Aircraft Using Endothermic Fuel," Journal of Aircraft, Vol. 29, No. 3, MayJune, 1992.

2. Edwards, T., "USAF Supercritical Hydrocarbon Fuels Interests," AIAA 93-0807, January 1993.

3. Escher, W.J.D., "A U.S. History of Airbreathing/ Rocket Combined-Cycle (RBCC) Propulsion for Powering Future Aerospace Transports, With a Look Ahead To The Year 2020," IS-030, presented at the $14^{\text {th }}$ International Symposium on Air Breathing Engines, September 1999.

4. CPIA/M5 Liquid Propellant Engine Manual, The Johns Hopkins University, Chemical Propulsion Information Agency, Unit No. 181-182, September 1999.

5. Linne, D.L., Meyer, M.L., Edwards, T., and Eitman, D.A., "Evaluation of Heat Transfer and Thermal Stability of Supercritical JP-7 Fuel," AIAA 973041, NASA TM-107485, July 1997.

6. Kumakawa, A., Sasaki, M., Takahashi, M., Sato, K., Sakamoto, H., Ono, F., Yatsuyanagi, N., Sano, K., and Higashino, K., "Experimental Study on Liquid Methane Cooled Thrust Chambers," Proceedings of $18^{\text {th }}$ International Symposium on Space Technology and Science, Vol. 1, pp. 41-50, May 1992.

7. Thurston, R.S., "Pressure Oscillations Induced By Forced Convection Heat Transfer to Two Phase and Supercritical Hydrogen: Preliminary Experiments," Los Alamos Scientific Laboratory report LAMS3070 (also N64-21055), May 1964.

8. Hendricks, R.C., Simoneau, R.J., and Friedman, R., "Heat-Transfer Characteristics of Cryogenic Hydrogen From 1000 to 2500 PSIA Flowing Upward in Uniformly Heated Straight Tubes," NASA TN D-2977, September 1965.

9. Hines, W.S. and Wolf, H. "Pressure Oscillations Associated With Heat Transfer to Hydrocarbon Fluids at Supercritical Pressures and Temperatures." ARS Journal, pp. 361-366, March 1962.

10. Faith, L.E., Ackerman, G.H., and Henderson, H.T., "Heat Sink Capability of Jet A Fuel: Heat Transfer and Coking Studies," NASA CR-72951, 1971.

11. Rousar, D.C., Gross, R.S., and Boyd, W.C.. "Supercritical Convection, Critical Heat Flux, and Coking Characteristics of Propane," AIAA-841263, June 1984.

12. Hitch, B.D., and Karpuk, M.E., "Experimental Investigation of Heat Transfer and Flow Instabilities in Supercritical Fuels," AIAA-97-3043, July 1997.

13. Hitch, B.D., and Karpuk, M.E., "Enhancement of Heat Transfer and Elimination of Flow Oscillations in Supercritical Fuels," AIAA-98-3759, July 1998.

14. Handbook of Single-Phase Convective Heat Transfer, S. Kakac, R.K. Shah, and W. Aung, John Wiley and Sons, 1987, pp. 18-27.

15. Green, J.M., Pease, G.M., and Meyer, M.L., "A Heated Tube Facility for Rocket Coolant Channel Research," AIAA 95-2936, 1995.

16. Meyer, M.L., "Electrically Heated Tube Investigation of Cooling Channel Geometry Effects," AIAA 952500, NASA TM-106985, 1995.

17. Edwards, T., "USAF Supercritical Hydrocarbon Fuels Interests," AIAA 93-0807. January 1993.

18. Ely, J.F., and Huber, M.L., "NIST Standard Reference Database 4-NIST Thermophysical Properties of Hydrocarbon Mixtures," February 1990. 


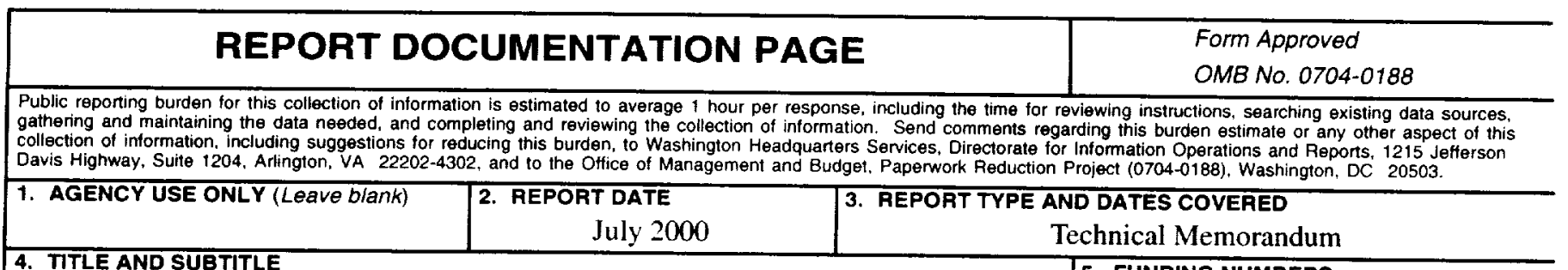

4. TITLE AND SUBTITLE

5. FUNDING NUMBERS

Investigation of Instabilities and Heat Transfer Phenomena in Supercritical

Fuels at High Heat Flux and Temperatures

6. AUTHOR(S)

Diane L. Linne, Michael L. Meyer, Donald C. Braun, and Dennis J. Keller

7. PERFOAMING ORGANIZATION NAME(S) AND ADDRESS(ES)

National Aeronautics and Space Administration

John H. Glenn Research Center at Lewis Field

Cleveland, Ohio 44135-3191

WU-523-61-13-00

9. SPONSORINGMONITORING AGENCY NAME(S) AND ADDRESS(ES)

National Aeronautics and Space Administration

Washington, DC 20546-0001

8. PERFORMING ORGANIZATION REPORT NUMBER

E-12392

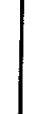

\section{SUPPLEMENTARY NOTES}

Prepared for the 36th Joint Propulsion Conference and Exhibit cosponsored by AIAA, ASME, SAE, and ASEE, Huntsville, Alabama, July 16-19, 2000. Diane L. Linne, Michael L. Meyer, and Donald C. Braun, NASA Glenn Research Center: Dennis J. Keller, RealWorld Quality Systems, 20388 Bonnie Bank Blvd., Cleveland, Ohio 44116. Responsible person, Diane L. Linne, organization code 5830, (216) 977-7512.

12a. DISTRIBUTIONAAVAILABILITY STATEMENT

12b. DISTRIBUTION CODE

Unclassified - Unlimited

Subject Categories: 26 and 28

Distribution: Nonstandard

This publication is available from the NASA Center for AeroSpace Information, (301) 621-0390.

13. ABSTRACT (Maximum 200 words)

A series of heated tube experiments was performed to investigate fluid instabilities that occur during heating of supercritical fluids. In these tests, JP-7 flowed vertically through small diameter tubes at supercritical pressures. Test section heated length, diameter, mass flow rate, inlet temperature, and heat flux were varied in an effort to determine the range of conditions that trigger the instabilities. Heat flux was varied up to $4 \mathrm{BTU} / \mathrm{in} .2 / \mathrm{s}$, and test section wall temperatures reached as high as $1950^{\circ} \mathrm{F}$. A statistical model was generated to explain the trends and effects of the control variables. The model included no direct linear effect of heat flux on the occurrence of the instabilities. All terms involving inlet temperature were negative, and all terms involving mass flow rate were positive. Multiple tests at conditions that produced instabilities provided inconsistent results. These inconsistencies limit the use of the model as a predictive tool. Physical variables that had been previously postulated to control the onset of the instabilities, such as film temperature, velocity, buoyancy, and wall-to-bulk temperature ratio, were evaluated here. Film temperatures at or near critical occurred during both stable and unstable tests. All tests at the highest velocity were stable, but there was no functional relationship found between the instabilities and velocity, or a combination of velocity and temperature ratio. Finally, all of the unstable tests had significant buoyancy at the inlet of the test section. but many stable tests also had significant buoyancy forces.

\section{SUBJECT TERMS}

JP-7 jet fuel; Thermal stability: Supercritical fluids; Heat transfer

\begin{tabular}{|c|c|c|}
\hline $\begin{array}{c}\text { 17. SECURITY CLASSIFICATION } \\
\text { OF REPORT } \\
\text { Unclassified }\end{array}$ & $\begin{array}{c}\text { 18. SECURITY CLASSIFICATION } \\
\text { OF THIS PAGE } \\
\text { Unclassified }\end{array}$ & $\begin{array}{c}\text { 19. SECURITY CLASSIFICATION } \\
\text { OF ABSTRACT } \\
\text { Unclassified }\end{array}$ \\
\hline
\end{tabular}

NSN 7540-01-280-5500

15. NUMBER OF PAGES

16. PRICE 32

DE

20. LIMITATION OF ABSTRACT

$\mathrm{AO} 3$ 

